\title{
Examining Uncertainties in the Linkage Between Global Climate Change and Potential Human Health Impacts in the Western USA -- Hexachlorobenzene (HCB) as a Case Study
}

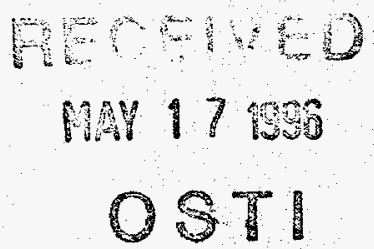

T.E. McKone, J.I. Daniels, and M. Goldman

OSTI

September 1994

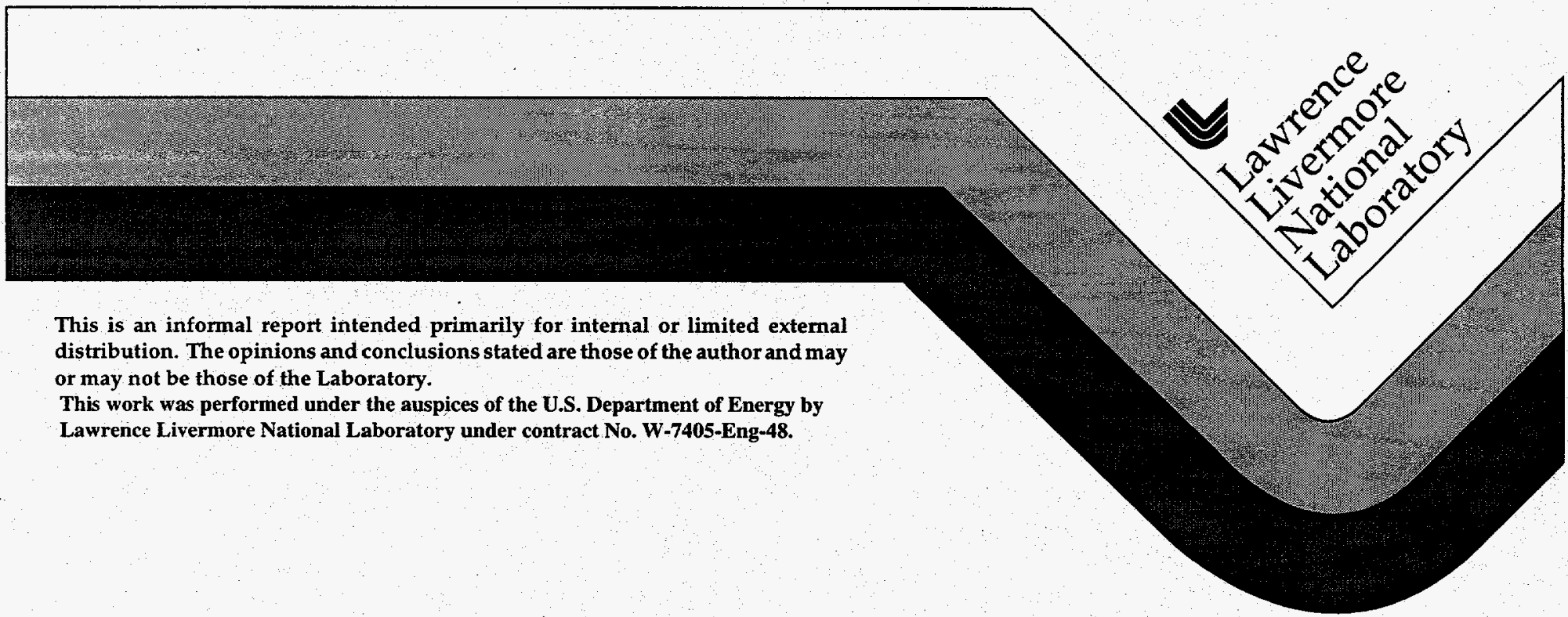


This document was prepared as an account of work sponsored by an agency of the United States Government. Neither the United States Government nor the University of California nor any of their employees, makes any warranty, express or implied, or assumes any legal liability or responsibility for the accuracy, completeness, or usefulness of any information, apparatus, product, or process disclosed, or represents that its use would not infringe privately owned rights. Reference herein to any specific commercial product, process, or service by trade name, trademark, manufacturer, or otherwise, does not necessarily constitute or imply its endorsement, recommendation, or favoring by the United States Government or the University of California. The views and opinions of authors expressed herein do not necessarily state or reflect those of the United States Government or the University of California, and shall not be used for advertising or product endorsement purposes.

This report has been reproduced directly from the best available copy.

Available to DOE and DOE contractors from the Office of Scientific and Technical Information P.O. Box 62, Oak Ridge, TN 37831

Prices available from (615) 576-8401, FTS 626-8401

Available to the public from the National Technical Information Service

U.S. Department of Commerce

5285 Port Royal Rd.,

Springfield, VA 22161 
DISCl AmMER

Portions of this docament may be illegible in electronic inage products. Images are produced from the best available original document. 
UCRL-ID-

Examining Uncertainties in the Linkage Between Global Climate Change and Potential Human Health Impacts in the Western USA-Hexachlorobenzene (HCB) as a Case Study

Prepared by

Thomas E. McKone

and

Jeffrey I. Daniels

Risk Sciences Center

Health and Ecological Assessment Division

University of California

Lawrence Livermore National Laboratory

P.O. Box 808 , L- 453

Livermore, CA 94551-9900

and

Marvin Goldman

University of California

Davis, CA 95616-8742

September 30, 1994

Supported with funding from

Western Regional Center for the Institute for

Global Environmental Change (WESTGEC)

3154 Wickson Hall

University of California at Davis

Davis, CA 95616

Contract No. 91-108 


\section{Table of Contents}

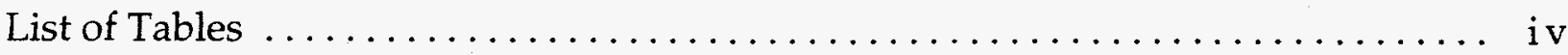

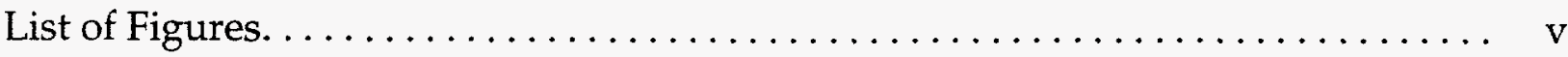

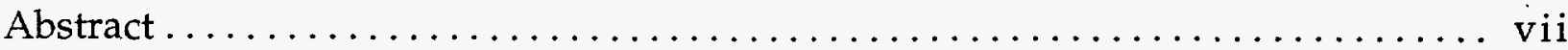

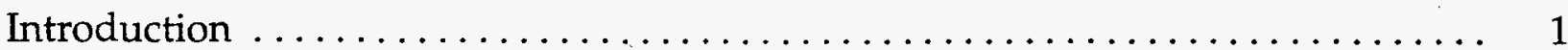

Problem Description. ................................. 2

Environmental Fate of HCB. . . . . . . . . . . . . . . . . . . 4

Transfer-Rate, Loss-Rate, and the Gain-Loss Equations . . . . . . . . . . 6

Relationship Between Molar Inventories and Health Risks . . . . . . . . 9

Uncertainty and Variability $\ldots \ldots \ldots \ldots \ldots \ldots \ldots \ldots \ldots \ldots \ldots \ldots \ldots \ldots \ldots \ldots \ldots \ldots$

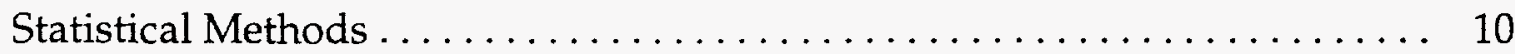

Physicochemical Properties........................... 11

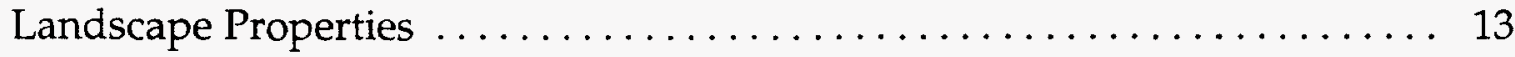

Case Study: Effect of Temperature Variation
on Health Effects Associated with HCB $\ldots \ldots \ldots \ldots \ldots \ldots \ldots \ldots \ldots \ldots \ldots 17$

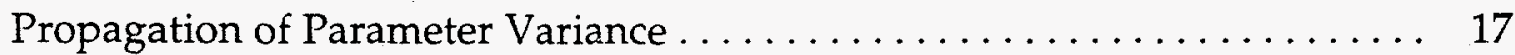

Results: Distribution of Health Risks for HCB With and Without Temperature/Climate Change .............. 19

Summary and Discussion $\ldots \ldots \ldots \ldots \ldots \ldots \ldots \ldots \ldots \ldots \ldots \ldots \ldots \ldots \ldots \ldots \ldots \ldots$

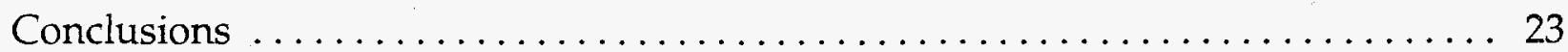

Appendix: Derivation of Transfer-Rate Constants $\ldots \ldots \ldots \ldots \ldots \ldots \ldots \ldots$

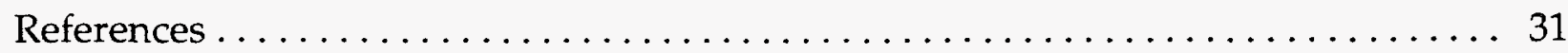




\section{List of Tables}

Table 1. -A matrix describing potential links between global climate

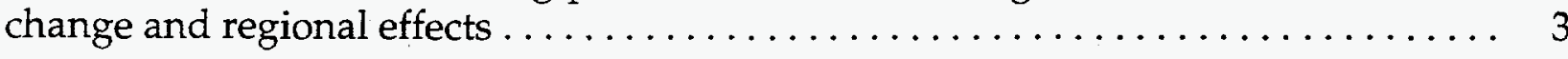

Table 2. Fugacity capacities for pure phases and environmental compartments. 6 Table 3. Definition of parameters used to construct fugacity capacities....... 7

Table 4. Summary of the processes by which contaminants are exchanged and lost among the three compartments $\ldots \ldots \ldots \ldots \ldots \ldots \ldots .9$

Table 5. Chemical properties for hexachlorobenzene $\ldots \ldots \ldots \ldots \ldots \ldots \ldots .12$

Table 6. Landscape properties for a typical air/water shed in the Western USA . . . . . . . . . . . . . . . . . . . . . . . . . . 14

Table 7. Correlation matrix for the distributions of temperature, rainfall, and wind speed in California cities . . . . . . . . . . . . . . . 16 


\section{List of Figures}

Figure 1. Illustration of an elementary, three-compartment chemical-potential model for assessing the environmental fate of hexachlorobenzene (HCB) emissions in a regional air basin ..............

Figure 2. Cumulative distribution of monthly average temperatures

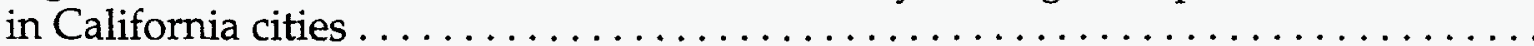

Figure 3. Cumulative average rainfall versus monthly average temperatures in California cities

Figure 4. Monthly average wind speed versus monthly average rainfall in California cities

Figure 5. Cumulative distributions of the cancer risk to an individual selected at random from the population living in the landscape receiving the postulated releases of hexachlorobenzene (HCB) to air and water with and without a postulated $5{ }^{\circ} \mathrm{C}$ temperature increase $\ldots \ldots \ldots \ldots \ldots \ldots$

Figure 6. Sensitivity of the health-risk prediction to model inputs for the calculation of risk in the absence of temperature increase

Figure 7. Sensitivity of the health-risk prediction to model inputs for the calculation of risk under the assumption that temperature increases up to $5{ }^{\circ} \mathrm{C}$ 


\title{
Examining Uncertainties in the Linkage Between Global Climate Change and Potential Human Health Impacts in the Western USA- Hexachlorobenzene $(\mathrm{HCB})$ as a Case Study
}

\author{
T. E. McKone*, J. I. Daniels*, and M. Goldmant \\ *University of California, Lawrence Livermore National Laboratory, Livermore, CA. \\ tUniversity of California at Davis, Davis, CA.
}

\begin{abstract}
Industrial societies have altered the earth's environment in ways that could have important, long-term ecological, economic, and health implications. In this paper we define, characterize, and evaluate parameter and outcome uncertainties using a model that links global climate change with predictions of chemical exposure and human health risk in the western region of the United States of America (USA). We illustrate the impact of uncertainty about global climate change on such potential secondary outcomes using as a case study the public health consequences related to the behavior environmentally of hexachlorobenzene (HCB), an ubiquitous multimedia pollutant. We begin by constructing a matrix that reveals the linkage between global environmental change and potential regional humanhealth effects that might be induced directly and/or indirectly by HCB released into the air and water. This matrix is useful for translating critical uncertainties into terms that can be understood and used by policy makers to formulate strategies against potential adverse irreversible health and economic consequences. Specifically, we employ a combined uncertainty/sensitivity analysis to investigate how the HCB that has been released is affected by increasing atmospheric temperature and the accompanying climate alterations that are anticipated and how such uncertainty propagates to affect the expected magnitude and calculational precision of estimates of associated potential human exposures and health effects. The results from this approach clearly indicate that a temperature increase of up to $5{ }^{\circ} \mathrm{C}$ should have no impact on the public-health consequences associated with $\mathrm{HCB}$ released into air and water in the western region of the USA.
\end{abstract}




\section{INTRODUCTION}

There is growing concern that human activities, principally those related to industrialization, are producing sustained global environmental changes that may lead to severe adverse impacts on a regional scale (Kempton and Craig, 1993). Although the precise degree of the changes and the exact magnitude of the consequences globally and regionally remain uncertain, there are implications that regionally the quality of life could be affected dramatically. Consequently, with an absence of complete information, decision makers at a regional level are confronted with the task of formulating defensible, proactive strategies that will both avert potential catastrophe and limit the burden of unnecessary costs for their society. Accordingly, to construct an effective strategy a decision maker must first interpret the significance of uncertainties (both qualitative and quantitative) in the scientific predictions that link regional effects with global environmental change and then balance these predictions against an uncertain regional economic forecast driven both by the global environment and by human behavior.

In this paper we apply a combined uncertainty/sensitivity analysis to one of the indirect regional impacts of global climate change-the public-health consequences related to the behavior environmentally of hexachlorobenzene (HCB), an ubiquitous multimedia pollutant. Specifically, we investigate how increasing atmospheric temperature and the climate alterations expected to accompany this temperature change will impact both the expected magnitude and the calculational precision of the estimated potential human exposures and health effects associated with releases of $\mathrm{HCB}$ to air and water.

We use a standard regional fugacity model of a type that is widely used in Europe, Canada, and the United States of America (USA) to characterize the environmental distribution and expected human exposure to $\mathrm{HCB}$ (van de Meent, 1990; Mackay and Paterson, 1991; and McKone, 1993). All inputs to this model are identified in terms of an arithmetic mean value $(\bar{x})$ and a coefficient of variation $(\mathrm{CV})$ that reflect uncertainty and variability of the input parameters. An uncertainty/sensitivity analysis is used to propagate parameter uncertainty and variability, and to compute output uncertainty. Outputs include concentrations of $\mathrm{HCB}$ in air, water, and soil as well as the human exposure and health risk associated with these levels of environmental contamination.

Based on a "with and without" analysis applied to climate change, we address model output uncertainty under two conditions. First, we assume that temperature and climate fluctuations follow historical patterns. Second, we assume that 
temperature and climate fluctuations follow historical trends with an uncertain temperature increase (e.g., up to a specified maximum) added to the existing fluctuations. We then examine the extent to which the temperature increase is expected to change the magnitude of the public health effects associated with the $\mathrm{HCB}$ released to air and water. We also explore the extent to which the variance in public health effects predictions are impacted by the uncertainty in temperature gain.

\section{PROBLEM DESCRIPTION}

Most discussion of global environmental change focuses on macroscopic variables, such as globally averaged surface temperature. These macroscopic variables are not often linked to those public health, ecological, or economic effects that are regional. As has been noted by MacCracken (1988), we do not have a physical model that we can set up in a laboratory to describe the Earth's climate. So, we are forced to rely on computational models that are theoretical with limited horizontal resolution. Accordingly, it is difficult to answer the key question of exactly where and to what extent warming will occur and what implications it will have locally. Yet, it is these secondary and more local effects, which include changes in rainfall, water levels, food production, air-pollution, etc., that are likely to be the significant ramifications of climate change and the precursors to any more deleterious consequences.

The World Health Organization (WHO) Task Group that prepared a report on the Potential Health Effects of Climatic Change divided potential health effects of climate change into two categories-direct and indirect effects (WHO, 1990). Among the direct effects are climate stress and adaptation, thermal factors, effects of ultraviolet radiation on human beings, and air pollution. Indirect effects associated with global climate change include impacts on food production and consumption, communicable and vector-borne diseases, and patterns of human migration. Among these sets of direct and indirect effects, we have selected "air pollution" for our uncertainty/sensitivity analysis. Table 1 illustrates an accounting system for linking a global environmental change (temperature increase) to regional environmental impacts, such as health effects.

To study the linkage just described, we selected for close examination the behavior of HCB in environmental media in the Western USA under conditions where we assume that over time global average temperature increases within some defined range (e.g., up to $5^{\circ} \mathrm{C}$ ). Such a change is considered plausible for the 
Table 1. A matrix describing potential links between global climate change and regional effects.

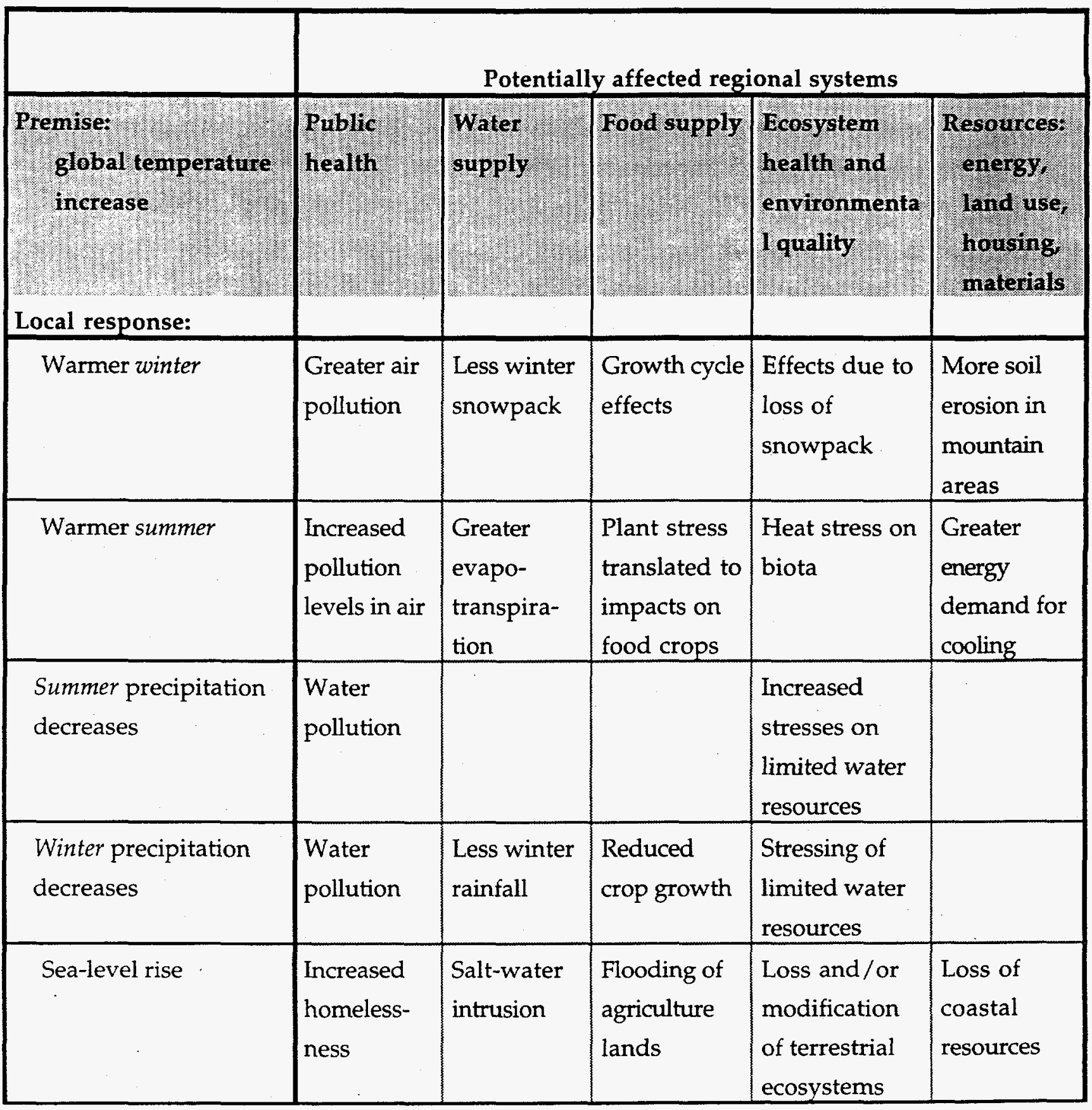


Western USA (MacCracken, 1988; NAS, 1991; Cess et al., 1993; Lindzen; 1994).

Therefore, up to a $5{ }^{\circ} \mathrm{C}$ change will be assigned in order to focus our efforts on the uncertainties in the connections between global climate changes and potential regional effects attributable to perturbations in the environmental fate of HCB.

\section{ENVIRONMENTAL FATE OF HCB}

Multimedia-compartment models are used for studying pollutant fate in environmental media (e.g., Thibodeaux, 1979; Mackay, 1979 and 1991; Mackay and Paterson, 1981 and 1982; Cohen and Ryan, 1985; McKone and Layton, 1986;

McKone et al., 1987; Whicker and Kirchner, 1987; and Cohen et al., 1990). In this investigation, we use a chemical-potential model that consists of three compartments for assessing the environmental fate of HCB emissions in a regional air basin. Air, surface soil, and surface water constitute the three compartments in our model. This mass-transfer model allows us to consider solution thermodynamics and environmentally driven advection processes-both of which are temperature dependent. In this model we are able to account systematically for gains and losses in each compartment and for the whole system in concert. Based on defined inputs of HCB to air and water, the model provides an algorithm for calculating contaminant concentrations that will appear eventually in air, water, and soil. The model structure is illustrated in Figure 1.

Our model uses a fugacity-based approach to describe chemical activity in environmental media at low concentrations. Fugacity-based modeling simplifies the mathematics involved in calculating partitioning. Fugacity-based models have been used extensively for modeling the transport and transformation of nonionic, organic chemicals in complex environmental systems (see Mackay, 1991).

Fugacity has units of pressure [pascal $(\mathrm{Pa})]$ and can be regarded physically as the chemical potential that is exerted by a chemical in one physical phase or compartment on another (Mackay, 1979 and 1991; and Mackay and Paterson, 1981 and 1982). For example, when two or more media are in thermodynamic equilibrium, the escaping tendency (the fugacity) of a chemical is the same in all phases. Also, fugacity models can be used to represent a nonequilibrium system that has achieved steady state by balancing gains and losses even though fugacities are not equal. 


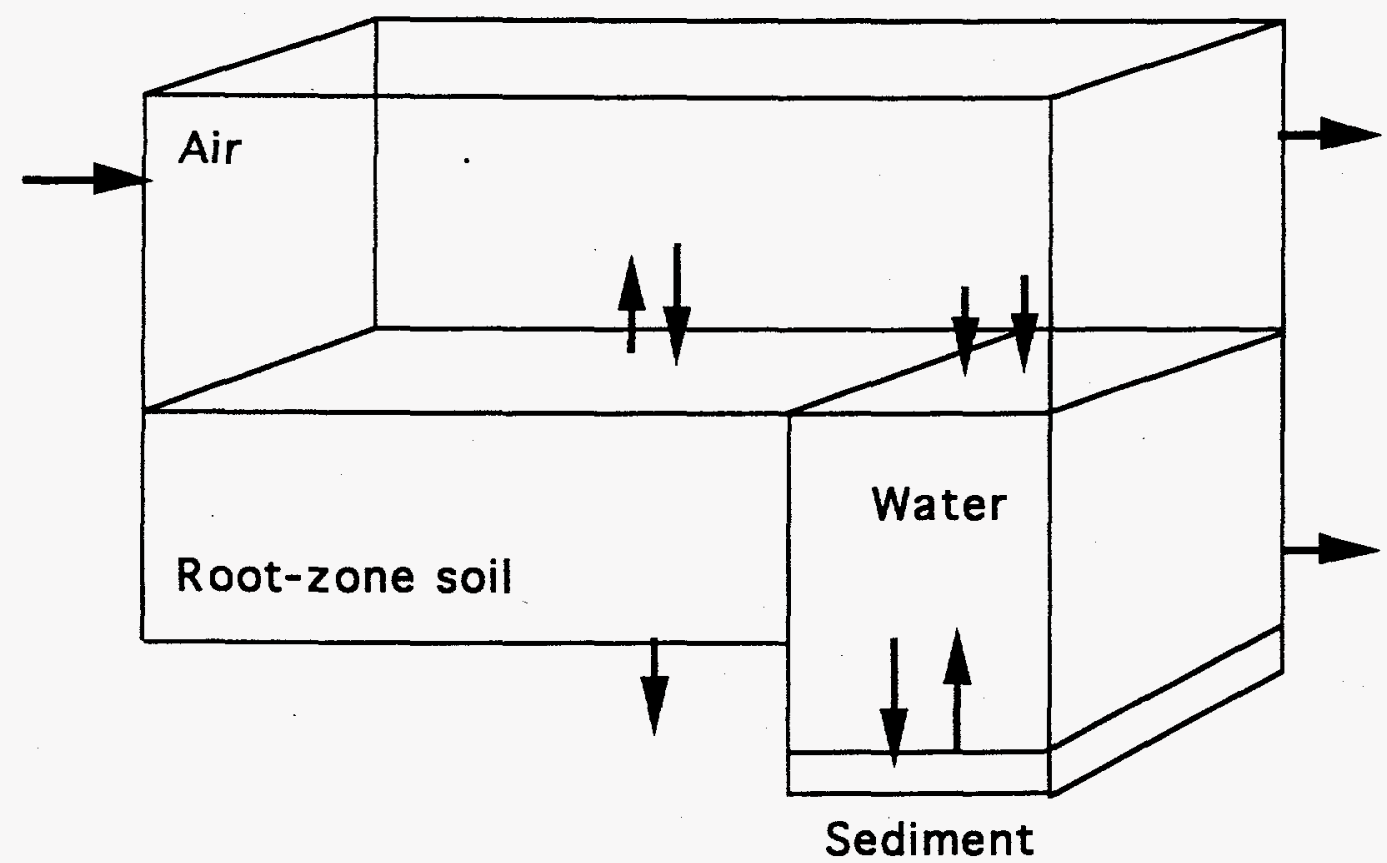

Figure 1. Illustration of an elementary, three-compartment chemical-potential model for assessing the environmental fate of hexachlorobenzene (HCB) emissions in a regional air basin.

At low concentrations, like those typical of environmental interest, fugacity, $f(\mathrm{~Pa})$, is linearly related to concentration $\mathrm{C}\left(\mathrm{mol} / \mathrm{m}^{3}\right)$ through the fugacity capacity, $Z\left(\mathrm{~mol} / \mathrm{m}^{3}-\mathrm{Pa}\right)$,

$$
C=f Z \text {. }
$$

The fugacity capacity, $Z$, depends on the physical and chemical properties of the chemical and on various characteristics of phase, such as temperature and density. The property that fugacities are equal at equilibrium allows for simple determination of $Z$ values from partition coefficients. For example, for two phases in thermodynamic equilibrium (phases 1 and 2),

$$
C_{1} / C_{2}=\left(f Z_{1}\right) /\left(f Z_{2}\right)=Z_{1} / Z_{2}=K_{1,2},
$$

where $C_{1}$ and $C_{2}$ are the concentrations in each phase, $Z_{1}$ and $Z_{2}$ are the fugacity capacities of each phase, and $K_{1,2}$ is a dimensionless partition coefficient, such as $\mathrm{K}_{\mathrm{ow}}$, the octanol-water partition coefficient. Table 2 provides a list of fugacity capacities (Z-values) for the phases and compartments used in this analysis of HCB. 
Table 2. Fugacity capacities $\left(\mathrm{mol} / \mathrm{m}^{3}-\mathrm{Pa}\right)$ for pure phases and environmental compartments.

\begin{tabular}{|r|c|c|}
\hline Compartment & $\begin{array}{c}\text { Fugacity- } \\
\text { capacity } \\
\text { symbol }\end{array}$ & Formula \\
\hline Pure air & $Z_{\text {air }}$ & $1 / \mathrm{RT}$ \\
\hline Air particles & $Z_{\mathrm{ap}}$ & $\frac{3 \times 10^{6}}{V P_{l}^{0} \mathrm{RT}}$ \\
\hline Bulk air & $Z_{\mathrm{a}}$ & $Z_{\mathrm{air}}+\mathrm{f}_{\mathrm{vap}} \times Z_{\mathrm{ap}}$ \\
\hline Puspended sediment & $Z_{\mathrm{wp}}$ & $K_{\mathrm{Dwp}} \times \rho \mathrm{s}_{\mathrm{wp}} \times Z_{\text {water }} \times \frac{1 \mathrm{~m}^{3} \text { water }}{1000 \mathrm{~L} \text { water }}$ \\
\hline Bulk water & $Z_{\mathrm{w}}$ & $Z_{\mathrm{water}}+\left(\rho \mathrm{b}_{\mathrm{w}} / \rho \mathrm{s}_{\mathrm{w}}\right) \times Z_{\mathrm{wp}}$ \\
\hline Soil particles & $Z_{\mathrm{sp}}$ & $K_{\mathrm{Dsp}} \times \rho \mathrm{s}_{\mathrm{sp}} \times Z_{\text {water }} \times \frac{1 \mathrm{~m}^{3} \text { water }}{1000 \mathrm{~L} \text { water }}$ \\
\hline Bulk soil & $Z_{\mathrm{s}}$ & $\alpha_{\mathrm{s}} Z_{\mathrm{air}}+\beta_{\mathrm{s}} Z_{\mathrm{water}}+\left(1-\phi_{\mathrm{s}}\right) Z_{\mathrm{sp}}$ \\
\hline
\end{tabular}

The fugacity capacity of a "bulk" compartment is calculated from the sum of the volume-fraction-weighted fugacity capacities of the constituent phases. Table 3 provides definitions of parameters used to construct the $Z$ values in Table 2 .

\section{Transfer-Rate, Loss-Rate, and the Gain-Loss Equations}

Mass transfer from one environmental medium to another is described in a nonequilibrium, steady-state (level III) fugacity model using mass-transfer $D$ values (Mackay, 1991). In the Mackay-type models, mass transfer is driven by the fugacity gradient across two adjacent compartments such that the flow, $F_{\text {in }}(\mathrm{mol} / \mathrm{h})$, is given by

$$
F_{\text {in }}=D_{1,2} \times\left(f_{1}-f_{2}\right),
$$

where $D_{1,2}$ is the fugacity-based transfer-rate constant across the boundary between medium 1 and medium 2 with units $\mathrm{mol} /(\mathrm{Pa}-\mathrm{h})$ and $f_{1}$ and $f_{2}$ are the fugacities of medium 1 and medium 2. This " $D$ " parameter can be structured to represent both diffusive and nondiffusive mass transfer. In using Eq. 3, we assume that the gradient from $f_{1}$ to $f_{2}$ occurs over a rather short distance relative to the depth of 
Table 3. Definition of parameters used to construct fugacity capacities.

\begin{tabular}{|c|c|}
\hline Symbol (units) & Description \\
\hline $\mathrm{R}\left(\mathrm{Pa}-\mathrm{m}^{3} / \mathrm{mol}-\mathrm{K}\right)$ & universal gas constant, $8.314 \mathrm{~Pa}-\mathrm{m}^{3} / \mathrm{mol}-\mathrm{K}$ \\
\hline $\mathrm{T}(\mathrm{K})$ & air temperature \\
\hline$V P_{l}^{\circ}(\mathrm{Pa})$ & subcooled liquid vapor pressure used to calculate sorption onto solids \\
\hline $\mathrm{H}\left(\mathrm{Pa}-\mathrm{m}^{3} / \mathrm{mol}\right)$ & $\begin{array}{l}\text { Henry's law constant, which expresses the ratio of equilibrium } \\
\text { activities of a chemical in air relative to water when the two phases are } \\
\text { well mixed }\end{array}$ \\
\hline$K_{\text {Dwp }}(\mathrm{L} / \mathrm{kg})^{\mathrm{a}}$ & $\begin{array}{l}\text { distribution coefficient for suspended sediment, which is the ratio at } \\
\text { equilibrium of chemical concentration attached to particles }(\mathrm{mol} / \mathrm{kg}) \text { to } \\
\text { chemical concentration in the water }(\mathrm{mol} / \mathrm{L})\end{array}$ \\
\hline$\rho \mathrm{s}_{\mathrm{wp}}\left(\mathrm{kg} / \mathrm{m}^{3}\right)$ & $\begin{array}{l}\text { density of the suspended sediment particles (not the bulk density of } \\
\text { the particles when mixed in solution). }\end{array}$ \\
\hline $\mathrm{K}_{\mathrm{Dsp}}(\mathrm{L} / \mathrm{kg})^{\mathrm{a}}$ & $\begin{array}{l}\text { distribution coefficient for soil, which is the ratio at equilibrium of } \\
\text { chemical concentration attached to particles (mol } / \mathrm{kg} \text { ) to chemical } \\
\text { concentration in the soil solution (mol } / \mathrm{L} \text { ) }\end{array}$ \\
\hline$\rho \mathrm{s}_{\mathrm{sp}}\left(\mathrm{kg} / \mathrm{m}^{3}\right)$ & $\begin{array}{l}\text { density of the actual soil particles (not the bulk density of the particles } \\
\text { when mixed in solution). }\end{array}$ \\
\hline$f_{\text {vap }}$ & volume fraction of particles in air \\
\hline$\alpha_{s}$ & volume fraction of air in the soil compartment \\
\hline$\underline{\beta_{\mathrm{s}}}$ & volume fraction of water in the compartment \\
\hline$\phi_{\mathrm{s}}$ & total void fraction in soil $\left(\alpha_{S}+\beta_{S}\right)$ \\
\hline$\rho b_{w}\left(\mathrm{~kg} / \mathrm{m}^{3}\right)$ & suspended-particle load in surface water \\
\hline$\rho \mathrm{s}_{\mathrm{w}}\left(\mathrm{kg} / \mathrm{m}^{3}\right)$ & ended-sediment particle density in pure phase \\
\hline
\end{tabular}

${ }^{a}$ Karickhoff (1981) has shown that the sorption coefficient for soils or sediments, $K_{D i}(i=w p$ or sp), can be related to the product of the organic-carbon partition coefficient, $\mathrm{K}_{\mathrm{oc}}$ and the fraction of organic carbon, $\mathrm{f}_{\mathrm{oc}}$ in a specific compartment. According to Mackay (1991), the value for $\mathrm{K}_{\mathrm{oc}}$ can be approximated as $0.4 \times \mathrm{K}_{\mathrm{ow}}$.

either medium 1 or 2 and that the two media are well-mixed so that the fugacity (or chemical potential) within the two media are mostly uniform.

The steady-state equations describing gains and losses in each of the three compartments are used to solve for the steady-state inventory in each compartment. 
The following equations express losses and gains for each of the three compartments: air (a), surface soil (s), and surface water (w).

$$
\begin{array}{ll}
\text { Air (a): } & S_{\mathrm{a}}+T_{\mathrm{sa}} N_{\mathrm{s}}+T_{\mathrm{wa}} N_{\mathrm{w}}=L_{\mathrm{a}} N_{\mathrm{a}} \\
\text { Surface soil (s): } \quad & T_{\mathrm{as}} N_{\mathrm{a}}=L_{\mathrm{s}} N_{\mathrm{s}} \\
\text { Surface water (w): } & \mathrm{S}_{\mathrm{w}}+T_{\mathrm{aw}} N_{\mathrm{a}}+T_{\mathrm{sw}} N_{\mathrm{s}}=L_{\mathrm{w}} N_{\mathrm{w}}
\end{array}
$$

In the equations above, an $N$ represents a compartment inventory, $\mathrm{L}$ represents total loss rate from a compartment, and the $T_{\mathrm{ij}}(\mathrm{i}, \mathrm{j}=\mathrm{a}, \mathrm{s}$, or $\mathrm{w})$ are transfer rate constants, with units of day-1, and express the fraction per unit time of the inventory of compartment $i$ that is transferred to compartment $j$. The product of an $N$ term and a $T$ term is the rate of change of inventory in mol/d. The product $L_{\mathrm{i}} N_{\mathrm{i}}$ represents all losses from compartment $i, \mathrm{~mol} / \mathrm{d}$. The terms $S_{\mathrm{a}}$ and $S_{\mathrm{w}}$, in equations 4 and 6 are, respectively, the rates of contaminant input to the air and water compartments, $\mathrm{mol} / \mathrm{d}$. Transfer-rate constants include landscape properties, chemical properties, fugacity capacities. The loss-rate constants, $L_{i}$, are defined in terms of transfer-and transformation-rate constants. Table 4 provides a list of the gains and losses by transport and transformation that are addressed in each environmental compartment.

In terms of fugacity, the balance in $\mathrm{mol} / \mathrm{d}$ is expressed as a loss from a compartment $i$ and transfer to a compartment $j$ in the form

$$
\text { loss }=\text { Area } \times \mathrm{v}_{\mathrm{ij}} \times \mathrm{Z}_{\mathrm{ik}} \times f_{\mathrm{i}},
$$

where Area $\left(\mathrm{m}^{2}\right)$ is that surface across which mass exchange occurs, $\mathrm{v}_{\mathrm{ij}}$ is the advection or diffusion velocity from $i$ to $j$ at the exchange boundary, $Z_{i k}$ is the fugacity capacity of the moving phase $k$ from $i$ to $j$, and $f_{i}$ represents the fugacity of compartment i. Equation 7 can also be written as

$$
\text { loss }=\mathrm{T}_{\mathrm{ij}} \mathrm{N}_{\mathrm{i}} \text {, }
$$

in which

$$
\begin{aligned}
& N_{i}=Z_{\mathrm{i}} f_{\mathrm{i}} \mathrm{V}_{\mathrm{i}}, \\
& T_{i j}=\frac{\operatorname{area} \times v_{i j}}{V_{i}} \frac{Z_{i k}}{Z_{i}}=\frac{v_{i j}}{d_{i}} \frac{Z_{i k}}{Z_{i}}, \text { and }
\end{aligned}
$$

$V_{i}$ is the compartment volume, $d_{i}$ is the compartment depth or thickness, and $Z_{i}$ is 
Table 4. Summary of the processes by which contaminants are exchanged and lost among the three compartments.

\begin{tabular}{l|l|l}
\hline Compartment & \multicolumn{1}{|c}{ Gains } & \multicolumn{1}{c}{ Losses } \\
\hline $\begin{array}{c}\text { (1) Air (both gas } \\
\text { phase and } \\
\text { particles in the } \\
\text { troposphere) }\end{array}$ & $\begin{array}{l}\text { diffusion from soil, } \\
\text { diffusion from surface water, } \\
\text { resuspension of deposited soil } \\
\text { particles, and } \\
\text { contaminant sources }\end{array}$ & $\begin{array}{l}\text { diffusion to soil, } \\
\text { diffusion to surface water, } \\
\text { deposition to soil, } \\
\text { deposition to surface water, and } \\
\text { chemical/physical transformation }\end{array}$ \\
\hline (2) Surface soil & $\begin{array}{l}\text { diffusion from air, } \\
\text { washout from air by rainfall, } \\
\text { and } \\
\text { dry deposition of air particles }\end{array}$ & $\begin{array}{l}\text { diffusion to air, } \\
\text { diffusion to deeper soil, } \\
\text { advection to deeper soil, } \\
\text { soil solution runoff, } \\
\text { erosion (mineral runoff) to surface water, } \\
\text { resuspension of soil particles, and } \\
\text { chemical/physical transformation }\end{array}$ \\
\hline (3) Surface water & $\begin{array}{l}\text { diffusion from air, } \\
\text { washout by rainfall, } \\
\text { deposition of atmospheric } \\
\text { particles, } \\
\text { soil solution runoff, } \\
\text { erosion (mineral runoff), and } \\
\text { contaminant sources }\end{array}$ & $\begin{array}{l}\text { sediment deposition, } \\
\text { diffusion to air, } \\
\text { diffusion to sediment, } \\
\text { surface-water outflow, and } \\
\text { chemical/physical transformation }\end{array}$ \\
\hline
\end{tabular}

the total fugacity capacity of compartment $\mathrm{i}$. This is the general approach that is described in the Appendix, which contains the derivation of the transfer-rate constants.

\section{Relationship Between Molar Inventories and Health Risks}

The purpose of this section is to define the computational model used for the dose estimates and to describe how uncertain and variable parameters are used in this model. Hexachlorobenzene is a likely human carcinogen with a carcinogenic slope factor (potency) for inhalation estimated to be $1.6 \mathrm{~kg}-\mathrm{d} / \mathrm{mg}$ based on studies involving laboratory animals (USEPA, 1993). The potential health risk is based on human contact through inhalation of contaminated air, ingestion of contaminated surface water, and ingestion of food contaminated by soil. The risk associated with these exposures is calculated as

$$
\text { Risk }=\left[\frac{\mathrm{N}_{\mathrm{a}}}{\mathrm{V}_{\mathrm{a}}} \times \frac{20 \mathrm{~m}^{3} / \mathrm{d}}{70 \mathrm{~kg}}+\frac{\mathrm{N}_{\mathrm{w}}}{\mathrm{V}_{\mathrm{w}}} \times \frac{2 \mathrm{~L} / \mathrm{d}}{70 \mathrm{~kg}}+\frac{\mathrm{N}_{\mathrm{s}}}{\mathrm{V}_{\mathrm{s}}} \times \mathrm{UDF} \text { (soil) }\right] \times \text { potency . }
$$


In this expression, the $\mathrm{N}_{\mathrm{i}}$ terms represent compartment inventories (mg), and the $V_{i}$ terms represent compartment volumes $\left(\mathrm{m}^{3}\right)$, where i equals $a, s$, or $w$. The $20 \mathrm{~m}^{3} /(70 \mathrm{~kg}-\mathrm{d})$ term is the assumed human contact by inhalation (for a 70-kg adult), the $2 \mathrm{~L} /(70 \mathrm{~kg}-\mathrm{d})$ term is the assumed human contact by ingestion of water (for a $70-\mathrm{kg}$ adult), and the UDF(soil) term is the unit dose factor for human contact 1 th $\mathrm{HCB}$ in soil as a result of ingestion of fruits, vegetables, grains, eggs, meat, and milk and is assigned a value of $0.0017 \mathrm{~kg}$ (soil) $/[\mathrm{kg}$ (body-weight)-day], which equates to $0.119 \mathrm{~kg}$ (soil) per day for a 70-kg adult, based on an analysis by McKone (1994). Because a goal of this investigation is to assess the relative impact on risk as a result of changes in chemical distribution following a positive change in temperature, we do not assess either the precision or variation of the cancer-potency factor and concentration-to-dose factors that appear in Eq. 11.

\section{UNCERTAINTY AND VARIABILITY}

In addition to the exposure and risk-related parameters that are described above, there are two classes of inputs to the multimedia transport and transformation model, which is used as a basis for characterizing potential health effects with and without climate change. These two classes of inputs are the physicochemical properties and the landscape properties. Each of these model inputs are described here in terms of an expected value (i.e., arithmetic mean, $\bar{x}$ ) and a coefficient of variation (CV). In the paragraphs below, we define the statistical moments used, the types of parameters needed in each data class, the $\bar{x}$, and the CV of the inputs, as well as temperature dependencies of the inputs, and correlations among all inputs.

\section{Statistical Methods}

The $\overline{\mathrm{x}}$ term is used to represent all inputs that are derived from a number of measured values-even those that might have geometric distributions. The value of $\bar{x}$ is computed by summing the measured observations and dividing this sum by the total number of observations. In this case, the $\mathrm{CV}$ is computed by dividing the arithmetic standard deviation $\left(\sigma_{\mathrm{n}}\right)$ by $\overline{\mathrm{x}}$.

For estimated input values, $\bar{x}$ and $C V$ are obtained from an estimation equation and the residual error of the estimation equation. 


\section{Physicochemical Properties}

Physicochemical properties include molecular weight, octanol-water partition coefficient, melting point, vapor pressure, Henry's law constant, diffusion coefficients in air and water, and the organic-carbon partition coefficient $\left(\mathrm{K}_{\mathrm{oc}}\right)$. The octanol-water partition coefficient is an intermedia transfer factor (ITF) that provides a measure of the extent of chemical partitioning between water and octanol at equilibrium and is used as a basis for estimating many other ITF parameters. The melting point is the temperature at which a compound makes the transition from a solid to a liquid phase. Vapor pressure is the pressure exerted by a chemical vapor in equilibrium with its solid and liquid phase. Water solubility is the upper limit on a chemical's dissolved concentration in pure water at a specified temperature. Henry's law constant is a measure at equilibrium of the ratio of chemical activity in the gas above a liquid to chemical activity in the liquid. Diffusion coefficients describe the movement of a molecule in a liquid or gas medium as a result of differences in concentration within the medium. They are used to calculate the dispersive component of chemical transport. The higher the diffusion coefficient, the more likely a chemical is to move in response to concentration gradients. The $\mathrm{K}_{\mathrm{oc}}$ provides a measure of chemical partitioning between organic carbon (in soils, rocks, and sediments) and water. The higher the $\mathrm{K}_{\mathrm{oc}}$, the more likely a chemical is to bind to the solid phase of soil or sediment than to stay in the liquid phase.

The distribution or sorption coefficient, $\mathrm{K}_{\mathrm{D}}$, is the ratio at equilibrium of chemical concentration attached to solids and/or particles $(\mathrm{mol} / \mathrm{kg}$ ) and chemical concentration in the solution, $\mathrm{mol} / \mathrm{L}$. When $\mathrm{K}_{\mathrm{oc}}$ is multiplied by the fraction organic carbon in a soil or sediment, we obtain an estimate of the soil/water or sediment/water partition coefficient.

Chemical transformations, which may occur as a result of biotic or abiotic processes, can have a profound effect on the persistence of contaminants in the environment. Accordingly, such reaction rates $\left(R_{i} s\right.$, where $i=a, s$, or $\left.w\right)$ need to be estimated for air, water, and soil.

Table 5 provides the mean and coefficient of variation for the chemical properties used in the chemical transport and transformation model. The ranges of values, uncertainties, and variabilities were obtained from a report by McKone et al. (1993). McKone et al. (1993) report 20 measured values of $K_{\text {ow }}$ with a mean and CV as listed in Table 5, and 12 measured values of water solubility, WS, with a mean 
Table 5. Chemical properties for hexachlorobenzene (HCB).

\begin{tabular}{|lccc|}
\hline \multicolumn{1}{|c}{ Description } & Symbol & $\begin{array}{c}\text { Arithmetic } \\
\text { mean }(\overline{\mathrm{x}})\end{array}$ & $\begin{array}{c}\text { Coefficient } \\
\text { of variation } \\
(\mathrm{CV})\end{array}$ \\
\hline Molecular weight $(\mathrm{g} / \mathrm{mol})$ & $\mathrm{MW}$ & 285 & 0 \\
Octanol-water partition coefficient & $\mathrm{K}_{\mathrm{ow}}$ & $1.20 \times 10^{6}$ & 2.2 \\
Melting point $(\mathrm{K})$ & $\mathrm{T}_{\mathrm{m}}$ & $2.31 \times 10^{2}$ & 0 \\
Vapor Pressure in $(\mathrm{Pa})$ & $\mathrm{VP}$ & $3.99 \times 10^{-4} \mathrm{a}$ & 1.1 \\
Solubility in mol/m3 & $\mathrm{WS}$ & $1.70 \times 10^{-5}$ & 0.12 \\
Henry's law constant $\left(\mathrm{Pa}-\mathrm{m}^{3} / \mathrm{mol}\right)$ & $\mathrm{H}$ & $38^{\mathrm{b}}$ & 1.2 \\
Diffusion coefficient in pure air $\left(\mathrm{m}^{2} / \mathrm{d}\right)$ & $\mathrm{D}_{\mathrm{air}}$ & $4.70 \times 10^{-1}$ & 0.1 \\
Diffusion coefficient; pure water $\left(\mathrm{m}^{2} / \mathrm{d}\right)$ & $\mathrm{D}_{\mathrm{water}}$ & $5.80 \times 10^{-5}$ & 0.1 \\
Organic carbon partition coefficient $\mathrm{K}_{\mathrm{oc}}$ & $\mathrm{K}_{\mathrm{oc}}$ & $5.00 \times 10^{4}$ & 2 \\
Partition coefficient in root-zone soil layer & $\mathrm{K}_{\mathrm{D}_{-} \mathrm{s}}$ & $6.00 \times 10^{2}$ & 1 \\
Partition coeffic. in surface water sediments & $\mathrm{K}_{\mathrm{D}_{-} \mathrm{d}}$ & $1.00 \times 10^{3} \mathrm{c}$ & 1 \\
Reaction rate constant in air $(1 / \mathrm{d})$ & $\mathrm{R}_{\mathrm{a}}$ & 0.00243 & 1.2 \\
Reaction rate constant, ground soil $(1 / \mathrm{d})$ & $\mathrm{R}_{\mathrm{s}}$ & 0.00052 & 0.5 \\
Reaction rate constant, surface water $(1 / \mathrm{d})$ & $\mathrm{R}_{\mathrm{W}}$ & 0.00052 & 0.5 \\
\hline
\end{tabular}

a Value of VP at $25^{\circ} \mathrm{C}$ in the application of the model; calculated using Antoine equation.

b Value of $\mathrm{H}$ at $25^{\circ} \mathrm{C}$; calculated as $\mathrm{H}=\mathrm{VP} / \mathrm{S}$, where VP is temperature dependent.

c Karickhoff (1981) has shown that the sorption coefficient for soils or sediments, $\mathrm{K}_{\mathrm{D}}$, can be related to the product of the organic-carbon partition coefficient, $\mathrm{K}_{\mathrm{oc}}$, and the fraction of organic carbon, $\mathrm{f}_{\mathrm{oc}}$ in a specific compartment. According to Mackay (1991), the value for $\mathrm{K}_{\mathrm{OC}}$ can be approximated as $0.4 \times \mathrm{K}_{\mathrm{ow}}$.

and CV also listed in Table 5. McKone et al. (1993) also report an Antoine equation for vapor pressure, VP, of $\mathrm{HCB}$ in the range 20 to $60^{\circ} \mathrm{C}$, from which the value of $\mathrm{VP}$ at any given temperature, $\mathrm{T}$ in ${ }^{\circ} \mathrm{C}$, can be obtained,

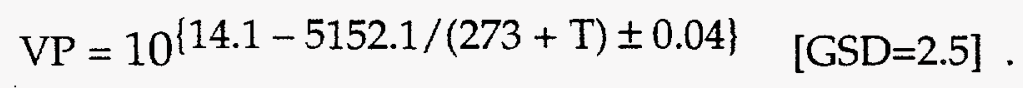

The geometric standard deviation (GSD) in this estimate corresponds to a CV of 1.1. The value in Table 5 corresponds to the VP at $25^{\circ} \mathrm{C}$. The Henry's law constant is calculated as $\mathrm{H}=\mathrm{VP} / \mathrm{WS}$ where VP is temperature dependent.

Also in Table 5, the mean value of the $\mathrm{K}_{\mathrm{oc}}$ is based on 10 measured values cited by McKone et al. (1993); the CV is based on our estimate of the reliability with 
which this parameter could be measured for soils in the Western USA. Distribution coefficients are based on the product of $\mathrm{K}_{\mathrm{OC}}$ and the organic carbon fractions in soil or sediment. Diffusion coefficients of HCB in air and water have listed values in Table 5 that are based on relatively reliable estimation methods.

Media-specific reaction rate constants for $\mathrm{HCB}$ in air, soil, and surface water were reported in the review of Howard et al. (1991), who estimate that the half life of $\mathrm{HCB}$ in the lower atmosphere is in the range of 3,750 to 37,500 hours (156 to 1,560 days) based on photo-oxidation as a removal process; that the half life of $\mathrm{HCB}$ in soil due to aerobic biodegradation is in the range of 2.7 to 5.7 years; and that the half life of $\mathrm{HCB}$ in surface water due to aerobic biodegradation is in the range of 2.7 to 5.7 years. Values for $\mathrm{HCB}$ reaction rates in Table 5 are based on the arithmetic mean and standard deviation of these ranges.

\section{Landscape Properties}

We developed a landscape data set that is representative of California and implicitly representative of much of the Western USA. The types of data needed to construct a landscape data set include (1) meteorological data, such as average annual wind speed, deposition velocities, air temperature, and depth of the mixing layer; (2) hydrological data, such as annual rainfall, runoff, soil infiltration, groundwater recharge, and surface-water depth and sediment loads; and (3) soil properties, such as bulk density, porosity, water content, erosion rates, and soil depth. In Table 6 we summarize the landscape data that is used to represent the California landscape. Also listed in Table 6 are the CVs that describe the variability and uncertainty in these data. These data were obtained from compilations by the U.S. National Oceanic and Atmospheric Administration (USNOAA, 1974), Soil Conservation Service (1975), U.S. Department of Agriculture (USDA, 1978), Gleick (1987), and van der Leeden et al. (1991).

Distributions of mean daily temperature, mean daily rainfall, and mean wind speed were constructed from monthly data for three California cities-Los Angeles, San Francisco, and Sacramento (USNOAA, 1974)—considered to be representative of climates in the Western USA. The reported mean and variance of the ratios of evapotranspiration, runoff, and recharge to rainfall are based on world-wide variations as compiled for the world water balance by continent provided in the Water Encyclopedia, (see van der Leeden et al., 1991, p. 59). 
Table 6. Landscape properties for a typical air/water shed in the western USA.

\begin{tabular}{|l|c|c|c|}
\hline \multicolumn{1}{|c|}{ Description } & Symbol & $\begin{array}{c}\text { Arithmetic } \\
\text { mean }(\overline{\mathrm{x}})\end{array}$ & $\begin{array}{c}\text { Coefficient } \\
\text { of variation } \\
(\mathrm{CV})\end{array}$ \\
\hline Contaminated area in $\mathrm{m}^{2}$ & Area & $4.10 \times 10^{10}$ & 0.1 \\
\hline Annual average precipitation $(\mathrm{m} / \mathrm{d})$ & rain & $1.11 \times 10^{-3}$ & 1 \\
\hline Land surface runoff $(\mathrm{m} / \mathrm{d})$ & runoff & $2.74 \times 10^{-4}$ & 0.26 \\
\hline Atmospheric dust load $(\mathrm{kg} / \mathrm{m} 3)$ & $\mathrm{f}_{\mathrm{vap}} \times \rho \mathrm{s}_{\mathrm{sp}}$ & $6.15 \times 10^{-8}$ & 0.1 \\
\hline Deposition velocity of air particles $(\mathrm{m} / \mathrm{d})$ & $\mathrm{v}_{\mathrm{d}}$ & $5.00 \times 10^{2}$ & 0.1 \\
\hline Ground-water recharge $(\mathrm{m} / \mathrm{d})$ & evapotrans & $7.10 \times 10^{-4}$ & 0.14 \\
\hline Evaporation of water from surface water $(\mathrm{m} / \mathrm{d})$ & evaporate & $4.38 \times 10^{-6}$ & 0.1 \\
\hline Thickness of the soil $(\mathrm{m})$ & $\mathrm{d}_{\mathrm{s}}$ & $2.00 \times 10^{0}$ & 0.1 \\
\hline Soil particle density $(\mathrm{kg} / \mathrm{m} 3)$ & $\rho \mathrm{s}_{\mathrm{sp}}$ & $2.60 \times 10^{3}$ & 0.1 \\
\hline Water content of soil $(\mathrm{volume}$ fraction) & $\beta_{\mathrm{s}}$ & $2.00 \times 10^{-1}$ & 0.1 \\
\hline Air content of soil $($ volume fraction) & $\alpha_{\mathrm{s}}$ & $1.00 \times 10^{-1}$ & 0.1 \\
\hline Fraction of land area in surface water & $\mathrm{f}_{\mathrm{arw}}$ & $8.15 \times 10^{-3}$ & 0.1 \\
\hline Average depth of surface waters $(\mathrm{m})$ & $\mathrm{d}_{\mathrm{w}}$ & $5.00 \times 10^{0}$ & 0.1 \\
\hline Suspended sediment in surface water $\left(\mathrm{kg} / \mathrm{m}^{3}\right)$ & $\rho \mathrm{b}_{\mathrm{w}}$ & $8.00 \times 10^{-1}$ & 0.1 \\
\hline Solid material density in sediment $\left(\mathrm{kg} / \mathrm{m}^{3}\right)$ & $\rho \mathrm{s}_{\mathrm{wp}}$ & $2.60 \times 10^{3}$ & 0.1 \\
\hline Ambient environmental temperature $(\mathrm{K})$ & $T$ & $2.88 \times 10^{2}$ & 0.014 \\
\hline Organic carbon fraction in upper soil zone & $\mathrm{f}_{\mathrm{oc}, \mathrm{s}}$ & $1.20 \times 10^{-2}$ & 0.1 \\
\hline Organic carbon fraction in suspended sediments & $\mathrm{f}_{\mathrm{oc}, \mathrm{d}}$ & $2.00 \times 10^{-2}$ & 0.1 \\
\hline Boundary layer thickness in air above soil $(\mathrm{m})$ & $\delta_{\mathrm{as}}$ & $5.00 \times 10^{-3}$ & 0.1 \\
\hline Yearly average wind speed $(\mathrm{m} / \mathrm{d})$ & $\mathrm{v}_{\mathrm{w}}$ & $3.38 \times 10^{5}$ & 0.24 \\
\hline
\end{tabular}

Figure 2 shows the pooled cumulative distribution of monthly average temperature (in the assumed absence of climate change) for these three California cities. (Moments of pooled populations are calculated as the fraction weighted values and not as moments of the sum.) Figure 3 provides a plot of monthly average rainfall versus monthly average temperature for these cities and reveals a rather strong negative correlation $(r=-0.82)$ of the variation in rainfall and the variation in temperature. This negative correlation suggests that, in California, rainfall corresponds to cooler temperatures (i.e., that rain is more likely to fall 


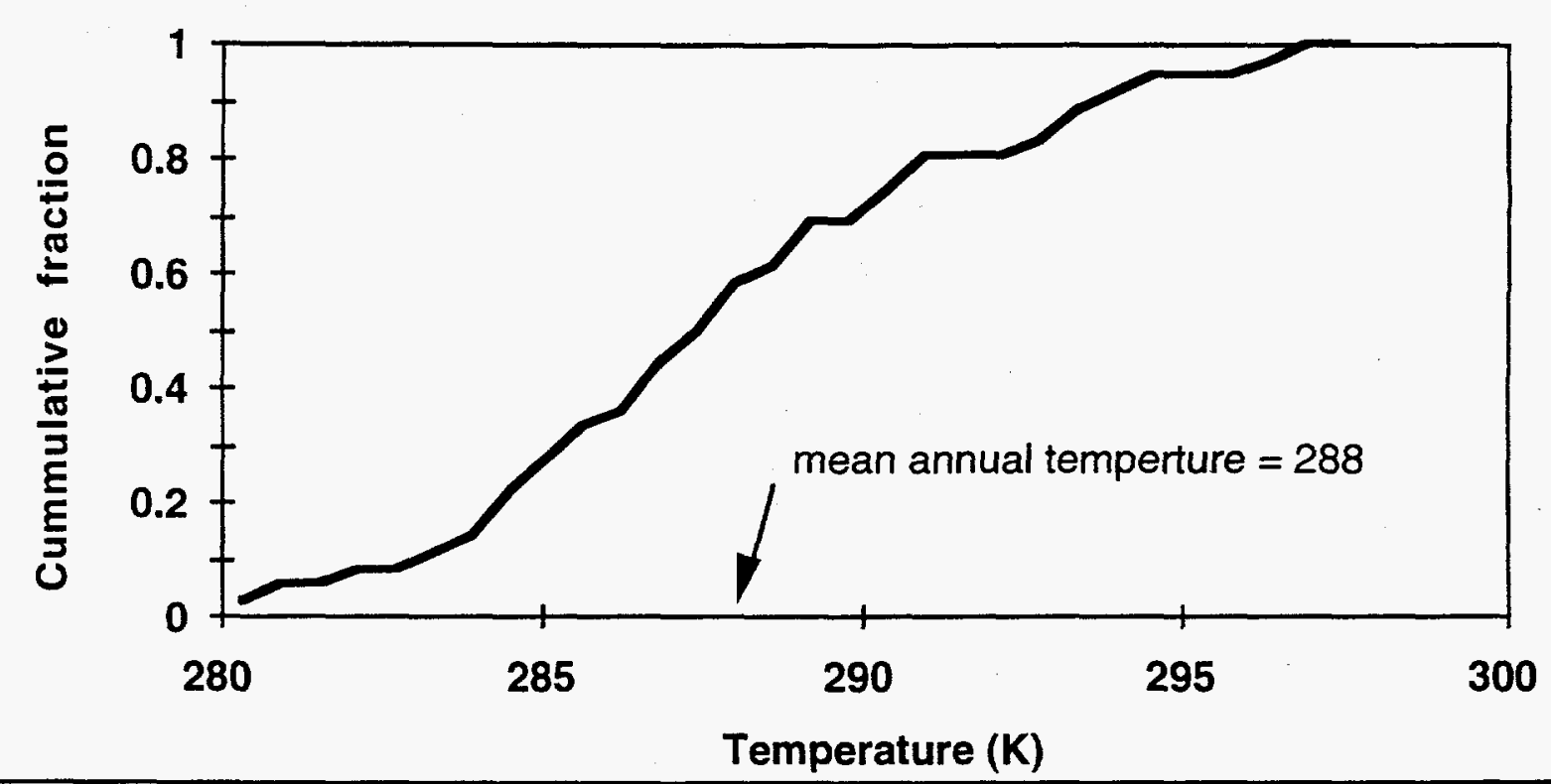

Figure 2. Cumulative distribution of monthly average temperatures in California cities $\left(\right.$ Temp $\left[{ }^{\circ} \mathrm{C}\right]=$ Temp $\left.[\mathrm{K}]-273\right)$.

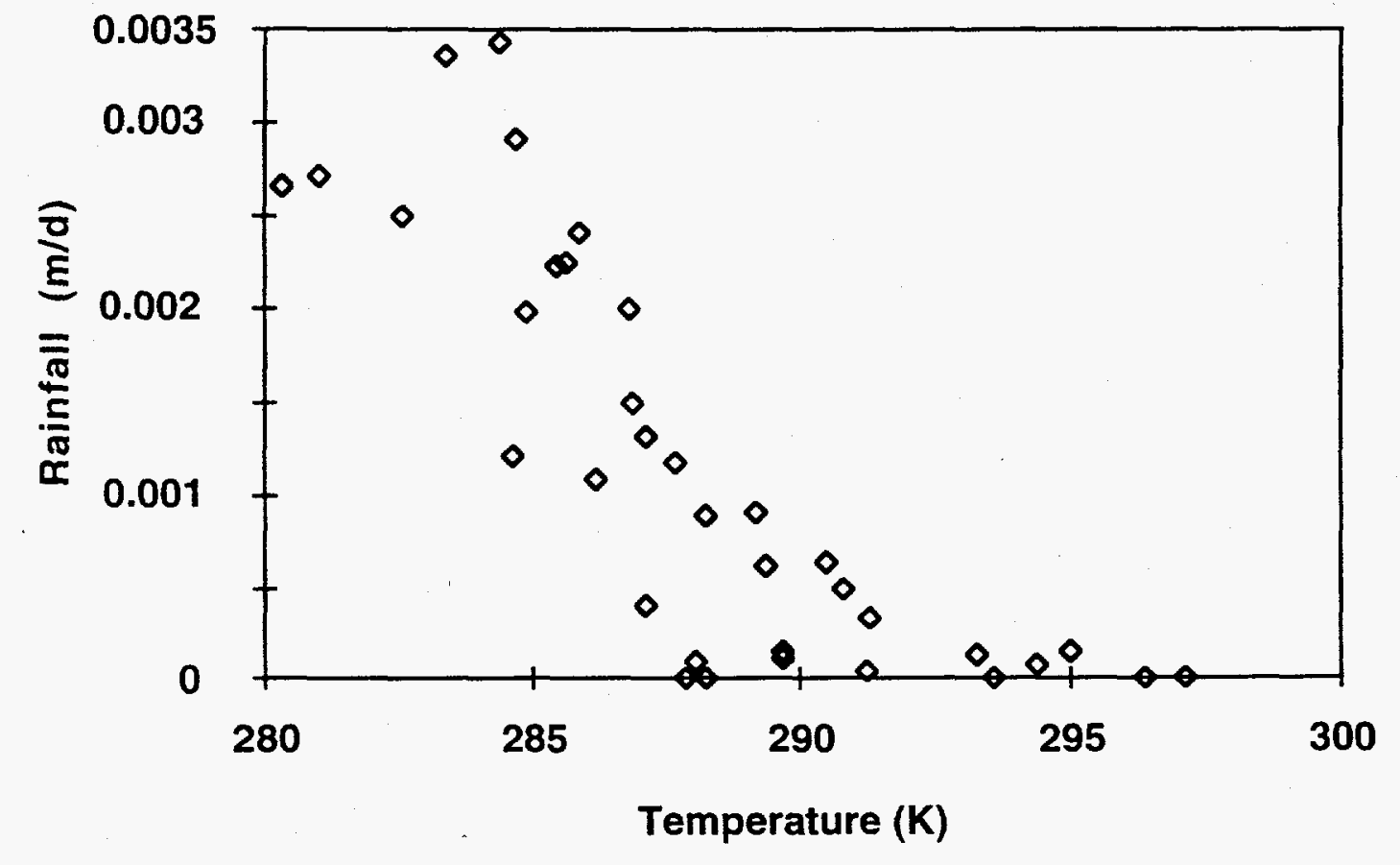

Figure 3. Monthly average rainfall versus monthly average temperature in California cities $\left(\right.$ Temp $\left[{ }^{\circ} \mathrm{C}\right]=$ Temp $\left.[\mathrm{K}]-273\right)$. 


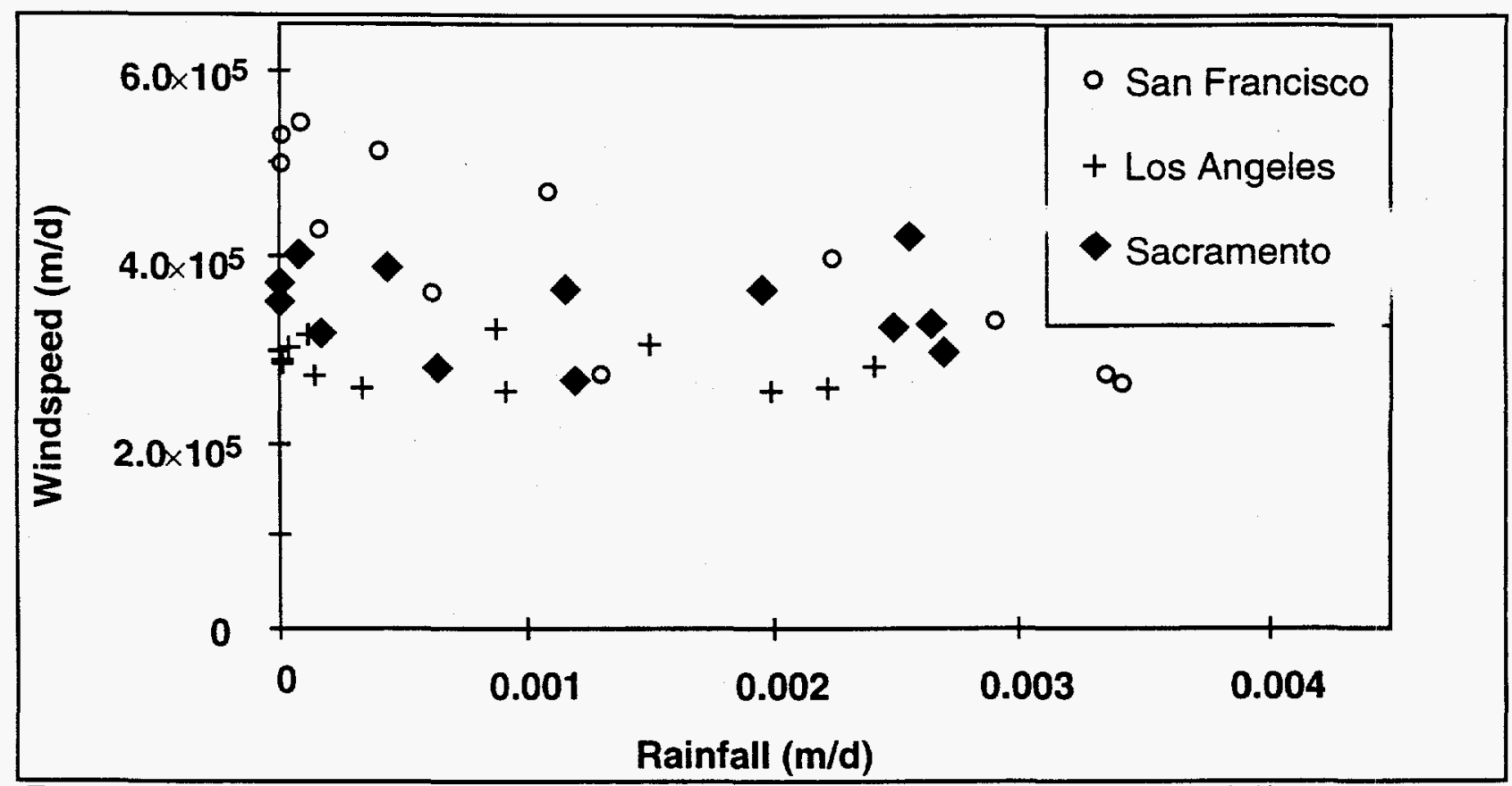

Figure 4. Monthly average wind speed versus monthly average rainfall in California cities.

during the winter months), which is in fact the case. This negative correlation also implies that rainfall is likely to decrease, if temperatures increase. Figure 4 provides a plot of monthly average wind speed versus monthly average rainfall and reveals a weak, but significant, negative correlation $(\mathrm{r}=-0.38)$ between rainfall and wind speed and suggests that higher winds occur during the rainy months. This correlation is strongest for San Francisco, and weakest for Los Angeles, with Sacramento having a value in between. This result also implies that less rainfall might correspond to less wind, which is significant when we consider that both wind and rain serve to decrease the inventory of contaminants released to the atmosphere. Table 7 provides a correlation matrix between rainfall, temperature, and wind speed.

Table 7. Correlation matrix for the distributions of temperature, rainfall, and wind speed in California cities.

\begin{tabular}{|c|c|c|c|}
\hline \multirow{4}{*}{$\begin{array}{c}\text { Temperature } \\
\text { Rainfall }\end{array}$} & Temperature & Rainfall & Wind speed \\
\cline { 2 - 4 } & -- & -0.82 & 0.05 \\
\cline { 2 - 4 } Wind speed & & -- & -0.38 \\
\cline { 2 - 4 } & & & -- \\
\hline
\end{tabular}




\section{CASE STUDY: EFFECT OF TEMPERATURE VARIATION ON HEALTH RISKS ASSOCIATED WITH HCB}

We selected for assessment in our case study the lipophilic, persistent, and ubiquitous chlorinated compound hexachlorobenzene (HCB). HCB is formed as a waste product in the production of several chlorinated hydrocarbons and is a contaminant in some pesticides. HCB is released to air as a fugitive emission from these hydrocarbon production facilities and is also released to air in flue gases and fly ash from waste incineration. HCB is persistent in the environment due to its chemical stability and resistance to biodegradation (Howard, 1989). We assess here the impact of temperature variation and average temperature increase on the distribution and fate of $\mathrm{HCB}$ and the resulting variation and change in the estimated public health impacts of $\mathrm{HCB}$ releases.

Using the regional fugacity model described above with transfer-factor relationships described in the Appendix of this paper, we simulate the distribution of HCB in the western region of the USA, which has the landscape properties listed in Table 6. The assumed inputs of HCB to this system are $1 \mathrm{~mol} /$ day to air and $10 \mathrm{~mol} /$ day to surface water. These conditions result in the expected values of mean annual concentrations of $\mathrm{HCB}$ in air, soil, and water of $36 \mathrm{ng} / \mathrm{m}^{3}, 15 \mathrm{ng} / \mathrm{kg}$, and $47 \mathrm{ng} / \mathrm{L}$, respectively, and correspond to an expected multimedia human exposure of $12 \mathrm{ng} / \mathrm{kg}$ - $\mathrm{d}$ of which $88.3 \%$ is attributable to air, $0.2 \%$ is attributable to soil, and $11.5 \%$ is attributable to water based on the multimedia distribution derived from Eq. 9 and the expressions in brackets in Eq. 11. Based on a cancer potency of $1.6[\mathrm{mg} / \mathrm{kg}-\mathrm{d}]^{-1}$ (USEPA, 1993), this corresponds to a projected lifetime risk for an individual selected at random from the population of $1.8 \times 10^{-5}$.

\section{Propagation of Parameter Variance}

Although it is not possible to set up an experiment that allows us to predict all of the impacts of a climate change, we can estimate outcomes using scientifically defensible models. The reliability of these models is determined by the precision of the model inputs and the accuracy with which the model addresses the relevant physical, chemical, and biological processes. Uncertainty in model predictions arise from a number of sources, including specification of the problem; formulation of the conceptual model; formulation of the computational model; estimation of parameter values; and calculation, interpretation, and documentation of the results. Of these, only the inherent variability of parameter values and uncertainties due to estimation of parameter values can be quantified in a straightforward manner. The 
analysis here addresses the propagation of parameter variance through a specified model to consider the reliability of our prediction of health risk and its relation to the variability of climate parameters.

There are two approaches by which we can assess hnw model predictions are impacted by model reliability and parameter variance-uncertainty analysis and sensitivity analysis. In order to address sensitivity and uncertainty, one can think of a model as producing an output $Y$, such as risk, that is a function of several input variables, $X_{i}$, that operate during time, $t$,

$$
Y=f\left(X_{1}, X_{2}, X_{3}, \ldots, X_{k}, t\right)
$$

As applied to a mathematical model, uncertainty analysis involves the determination of the variation or imprecision in the output function based on the collective variation of the model inputs, whereas sensitivity analysis involves the determination of the changes in model response as a result of changes in individual model parameters.

\section{Uncertainty Analysis}

Describing uncertainty in the output variable, $Y$, involves quantification of the range of $Y$, its arithmetic mean value, the arithmetic or geometric standard deviation of $Y$, and upper and lower quantile values of $Y$, such as the $5 \%$ lower bound and $95 \%$ upper bound. Convenient tools for presenting such information are the probability density function (PDF) or the cumulative distribution function (CDF) for Y. However, the PDF or CDF of Y can often only be obtained when we have meaningful estimates of the probability distributions of the input variables $X_{i}$.

\section{Sensitivity Analysis}

The goal of a sensitivity analysis is to rank the input parameters on the basis of their contribution to variance in the output. Sensitivity analyses can be either local or global. A local sensitivity analysis is used to examine the effects of small changes in parameter values at some defined point in the range of outcome values. A global sensitivity analysis quantifies the effects of variation in parameters over their entire range of values. A global sensitivity analysis requires an uncertainty analysis as a starting point. The variance in the outcome is compared to the variance of the inputs. 


\section{Monte Carlo Methods}

In a Monte Carlo analysis, each $X_{i}$ is represented by a PDF that defines both the range of values for the parameter and the likelihood that the parameter has a value in any subinterval of that range. In an unmodified Monte Carlo method, simple random sampling is used to select each member of the input parameter set.

The moments of the uncertain estimation of risk, both with and without climate change, were determined using version 3.0 of the computer software Crystal Ball ${ }^{\circledR}$ (Decisioneering, 1988-1993, 1994), which performs a Monte Carlo simulation to propagate uncertainty in a spreadsheet model. Inputs were taken from the $99.9 \%$ confidence interval of all input parameter distributions. The outcome moments tallied and used in the analysis of variance include the arithmetic mean and variance. These moments are used to calculate the $\mathrm{CV}$.

The number of repetitions required for each simulation set is determined by requiring consistent values of the first and second moments of the distribution from one simulation set to another, when a different random seed is used.

In addition to characterizing overall variance in the predictions of risk, the purpose of this analysis is to rank the relative importance of the model inputs. When Monte Carlo methods are used to propagate outcome variance, there are several methods for ranking uncertainty, including correlation coefficients, regression coefficients, rank correlation, and rank regression (IAEA, 1989). We made use of rank correlations to define the relative contribution of parameter variance to outcome variance.

\section{Results: Distribution of Health Risks For HCB With and Without Temperature/Climate Change}

Our objectives in this study are (1) to examine the extent to which an annual average temperature increase of up to $5^{\circ} \mathrm{C}$ is expected to change both the magnitude and the variability of the health effects associated with the HCB released to air and water and (2) to explore the extent to which the variance in health effects predictions are impacted by the uncertainty in temperature change.

Figure 5 shows the cumulative distribution of the risk to an individual selected at random from the population living in the landscape (i.e., Western USA) receiving the postulated releases of $\mathrm{HCB}$ to air and water. From this figure, we see that without the postulated increase of temperature the expected value of lifetime risk is $1.9 \times 10^{-5}$ with $C V=1.9$, and that with the postulated temperature increase the expected value of lifetime risk is $1.5 \times 10^{-5}$ with $C V=2.1$. Thus, we observe that with 


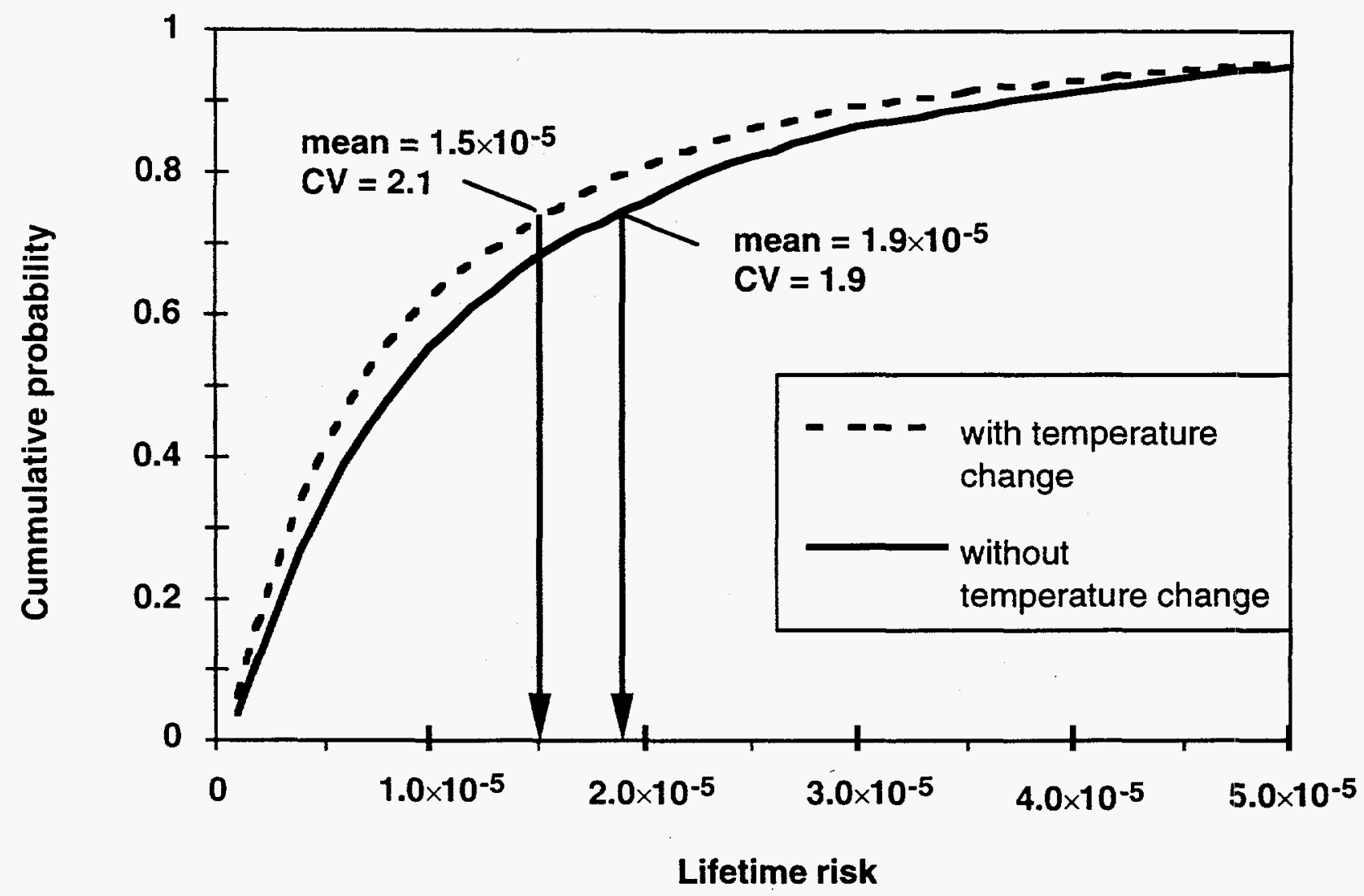

Figure 5. Cumulative distributions of the cancer risk to an individual selected at random from the population living in the landscape receiving the postulated releases of HCB to air and water with and without a postulated $5{ }^{\circ} \mathrm{C}$ temperature increase.

the postulated increase of temperature, the predicted risk is lower than it is without the increase. In contrast, the uncertainty and variability about this predicted risk, as expressed by the $\mathrm{CV}$ is greater with the postulated temperature increase. The predicted value of cancer risk decreases in a warmer climate, because in a warmer climate, under conditions of steady-state mass balance, more HCB is in the air than in other compartments, and HCB decomposes in air and does not persist as long in air as in other compartments. Thus, increasing the relative amount of HCB that is partitioned to air, serves to decrease the ratio of total inventory to source and lowers the predicted risk.

Understanding why the $\mathrm{CV}$ is higher in the warmer climate is not as straight forward. Accordingly, in order to better understand how the observed differences in $\mathrm{CV}$ come about, we carried out an analysis of variance in order to determine the 
amount of outcome (cancer risk) variance that is attributable to individual parameters under the with and without temperature change scenarios.

We used a rank correlation applied to our Monte Carlo analysis results in order to determine which parameters contribute to the variance in predicted cancer risk under the with and without temperature increase scenarios. Rank correlation methods normalize the sets of input and outcome values according to rank. A standard correlation on ranks is used to assess the percent of outcome variance attributable to particular inputs (IAEA, 1989). Figures 6 and 7 show the results of this analysis. Each figure provides a histogram plot of the amount of variance in cancer risk attributable to the variance of particular model inputs. In each case only the parameters with the ten largest contributions to variance are listed. The list of parameters is similar in both the with and without analysis. However, in the "without" case, $79 \%$ of the variance in risk is attributable to variance in just three inputs-HCB vapor pressure, VP; annual average temperature, Temp, and annual average rainfall, rain-and almost all of the remaining variance is attributable to four other parameters. In contrast, in the "with" case, the amount of variance attributable to VP, Temp, and rain go down to $76 \%$ and contributed variance is spread out more among the list of inputs. Because outcome from the "with" uncertainty analysis depends more on parameters having a larger variance, the estimated risk with a postulated temperature rise has a CV that increases relative to the "without" case, even though the estimated magnitude of risk decreases.

\section{SUMMARY AND DISCUSSION}

In this paper we apply a combined uncertainty/sensitivity analysis to one of the indirect regional impacts of global climate change-the public health consequences related to the behavior environmentally of hexachlorobenzene (HCB), an ubiquitous multimedia pollutant. Specifically, we investigate how increasing atmospheric temperature and the climate alterations expected to accompany this temperature change will impact both the expected magnitude of and the calculational precision for estimating the human exposure and health effects associated with release of hexachlorobenzene (HCB) to air and water.

An uncertainty/sensitivity analysis is used to propagate parameter uncertainty and variability and compute output uncertainty. Outputs include concentrations of HCB in air, water, and soil and the human health risk associated with these levels of environmental contamination. 


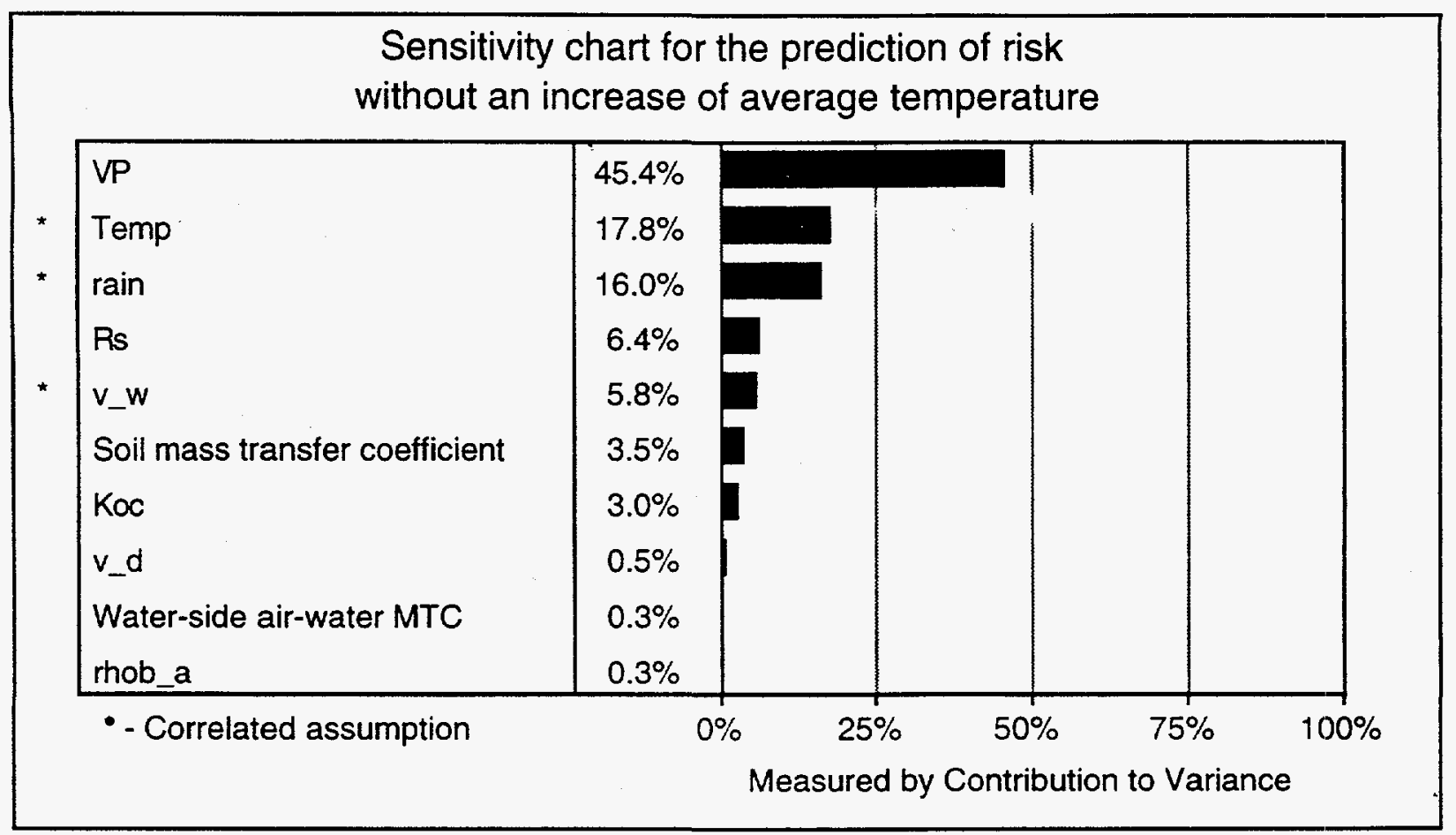

Figure 6. Sensitivity of the health-risk prediction to model inputs for the calculation of risk in the absence of temperature increase.

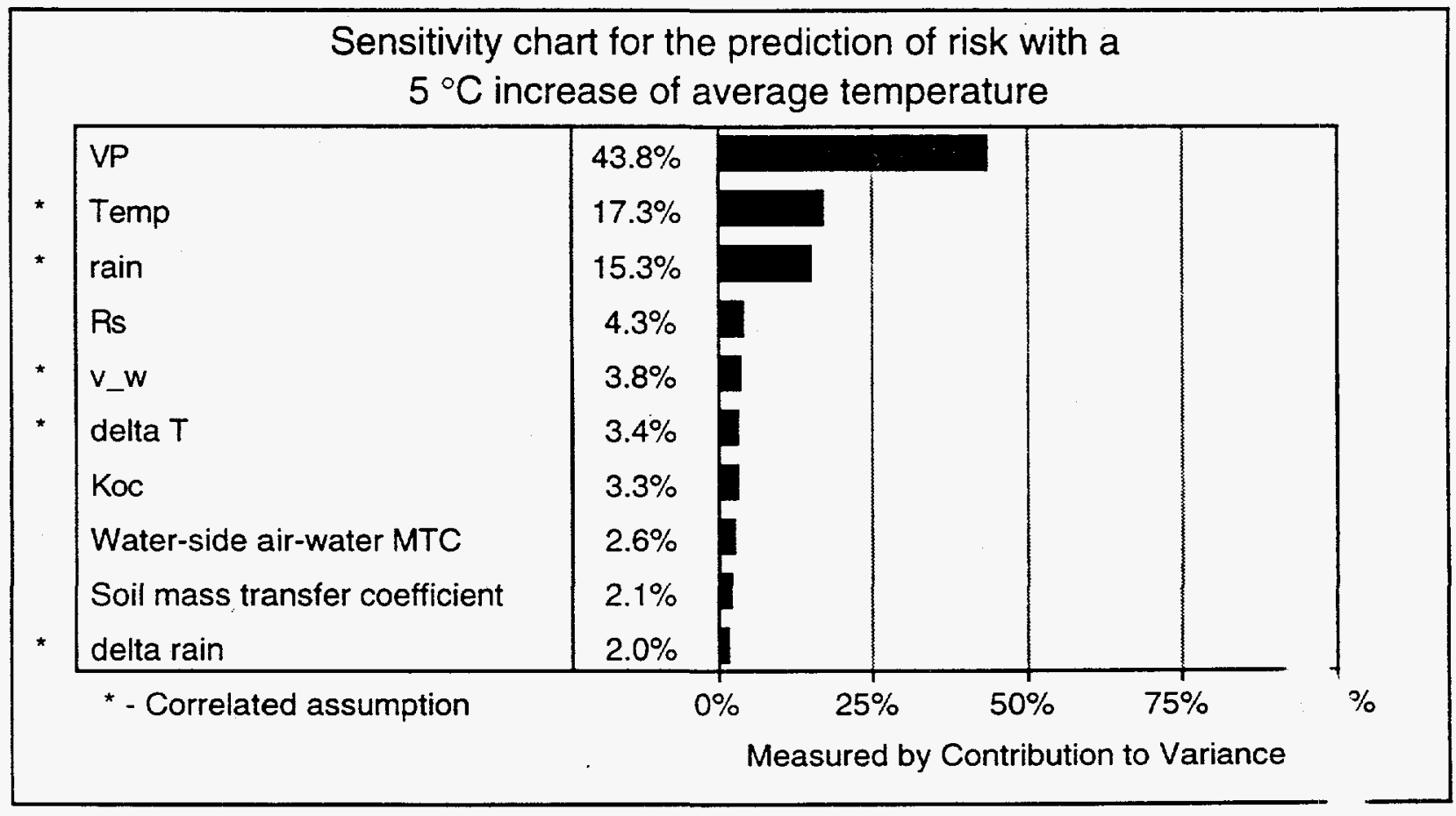

Figure 7. Sensitivity of the health-risk prediction to model inputs for the calculation of risk under the assumption that temperature increases up to $5^{\circ} \mathrm{C}$. 
Based on a "with and without" analysis applied to climate change, we address model output uncertainty under two conditions. First, we assume that temperature and climate fluctuations follow historical patterns. Second, we assume that temperature and climate fluctuations follow historical trends with an uncertain temperature increase added to the existing fluctuations. We then examine the extent to which the temperature increase is expected to change both the magnitude and the variability of the health effects associated with the HCB released to air and water. We also explore the extent to which the variance in health effects predictions are impacted by the uncertainty in temperature gain.

Although these changes are not significant they do reveal an important impact of temperature change on secondary impacts. The month-to-month variation of temperature is small relative to the variance in the projected population risk. The $\mathrm{CV}$ of month-to-month temperature variation without climate change is only 0.014 . The postulated average temperature increase of $2.5^{\circ} \mathrm{C}$ is less than $1 \%$ of the variance of the absolute average monthly temperatures among the selected California cities. Thus, we have in effect almost doubled the temperature variability in the risk model (from 0.014 to 0.024 ). The result is that the expected value of risk goes down $21 \%$ and the variance in this prediction goes up $20 \%$. The apparent amplification of variance is attributable to the correlation of other climate parameters with variations in temperature. Because we have assumed that existing correlations between monthly-average rainfall and monthly-average temperature and between monthly-average wind speed and monthly average rainfall would apply in a world where the monthly average temperatures increase, we observe a larger impact on exposure to $\mathrm{HCB}$ and health risks than would have been the case had we carried out this risk assessment under the assumption that only the temperature increases while the variance in other climate parameters remains unchanged.

\section{CONCLUSIONS}

Kempton and Craig (1993) point out that ideally policy advisors should communicate risks to the public in an accessible language. In practice, this language becomes monetary when we base social welfare choices on the value of a statistical human life, which could range as high as $\$ 2$ to $\$ 9$ million (Hall et al., 1992). This value is then compared to the costs of intervention designed to eliminate, control, stabilize, or reduce a specific health or safety problem. Because of the magnitude of the costs, it is imperative that the uncertainties in the predictions be linked to the 
proposed solutions. Accordingly, in our example we demonstrate that by addressing uncertainty, a decision maker can be shown that even though local temperatures may increase up to $5{ }^{\circ} \mathrm{C}$ in the western region of the USA, realistically, there will be no benefit from regulating the introduction into the environment of the volatile and ubiquitous chemical HCB. Therefore, unless global environmental change can be predicted with greater certainty and outcomes determined beyond a reasonable doubt, policy decisions should be made and defended with the best possible analytical evidence available, which includes incorporating analyses of uncertainty into all assessments, especially evaluations performed on a case-by-case basis.

We conclude that the approach we illustrated here will lead to a defensible strategy for assessing the effectiveness of policies that address the predicted adverse effects of global environmental changes on the Western USA. Furthermore, our approach is consistent conceptually with the procedures and recommendations of others for addressing uncertainties associated with predicting the effects of global environmental change (e.g., MacCracken, 1988 and 1991; Cess et. al., 1993; Lave and Dowlatabadi, 1993; Lindzen, 1994; and Lane et al, 1994). 


\section{APPENDIX \\ DERIVATION OF TRANSFER-RATE CONSTANTS}

\section{The Air (a) Compartment}

The air compartment is represented by a simple box model in which losses include deposition to soil and surface water; convective losses; and transformation losses. In the box model used for air, the inventory, $N_{\mathrm{a}}$ in mol, is described by solving equations 4 to 6 in the text. $L_{\mathrm{a}}$ is the sum of all loss-rate constants from the air compartment,

$$
L_{\mathrm{a}}=T_{\mathrm{as}}+T_{\mathrm{aw}}+T_{\mathrm{ao}}+R_{\mathrm{a}} \text {, }
$$

where $L_{\mathrm{a}} N_{\mathrm{a}}$ is the sum of all losses from the air compartment, mol/d; $T_{\text {sa }} N_{\mathrm{s}}$, and $\mathrm{T}_{\text {wa }} N_{\mathrm{w}}$ are the gains from surface soil and water, mol/d; $T_{\text {as }}$ and $T_{\text {aw }}$ are the rate constants for deposition losses to soil and water, day ${ }^{-1} ; T_{\text {ao }}$ is the rate constant for convective losses, day $^{-1}$ and $R_{\mathrm{a}}$ is the rate constant for transformation losses, day ${ }^{-1}$.

According to Benarie (1980), the long-term average pollutant concentration in a region bordered by a box model with volume $V_{\mathrm{a}}$ and pollution source, $S_{\mathrm{a}}$ in $\mathrm{mol} / \mathrm{d}$, is given by

$$
C_{\text {air }}=N_{\mathrm{a}} / V_{\mathrm{a}}=\frac{c S_{\mathrm{a}}}{\operatorname{Area} \times v_{\mathrm{w}}},
$$

where $c$ is a unitless proportionality constant; Area is the area of the region being modeled, and $\mathrm{v}_{\mathrm{w}}$ is the long-term average wind speed in $\mathrm{m} / \mathrm{d}$. This implies that the inverse of the rate constant, $T_{\mathrm{ao}}$, is the convective residence time and is given by the expression, $\mathrm{c} \mathrm{d} \mathrm{d}_{\mathrm{a}} / \mathrm{v}_{\mathrm{w}}$, where $d_{\mathrm{a}}$ is the atmospheric mixing height. Based on a model for area sources developed by Turner (1970), the constant $c$ can be estimated as $4.3 \sqrt{\text { Area }} / \mathrm{d}_{\mathrm{a}}$, where $\sqrt{\text { Area }}$ is the cross-sectional length of an assumed square area containing the source $S_{\mathrm{a}}$. Making the appropriate substitutions gives the following expression for the convective loss-rate constant in the air compartment:

$$
T_{\text {ao }}=\frac{0.23 v_{\mathrm{w}}}{\sqrt{\text { Area }}}
$$


The rate constant, $T_{\text {as }}$, accounts for gross diffusion, rain-water washout, and particle-deposition losses from air to ground-surface soil.

$$
T_{\text {as }}=\left(1-f_{\text {arw }}\right) \times \frac{\left(Y_{\text {as }}+\text { rain } \times Z_{\text {water }}+\mathrm{v}_{\mathrm{d}} \times Z_{\text {ap }} \times \frac{\rho \mathrm{b}_{\mathrm{a}}}{\rho \mathrm{s}_{\mathrm{s}}}\right)}{\left(Z_{\mathrm{a}} \times \mathrm{d}_{\mathrm{a}}\right)} .
$$

In this expression, $\mathrm{f}_{\mathrm{arw}}$ is the fraction of land area that is covered by surface water; $\rho b_{a}$ is the particle loading in the air, $\mathrm{kg} / \mathrm{m}^{3}$, and $\rho \mathrm{s}_{\mathrm{s}}$ is the particle density, $\mathrm{kg} / \mathrm{m}^{3}$. The air-compartment mixing depth, $d_{a}$, is $700 \mathrm{~m}$. The net diffusion from air ground-surface soil is given by $Y_{\mathrm{as}}\left(f_{\mathrm{a}}-f_{\mathrm{s}}\right)$. Thus, $Y_{\mathrm{as}} f_{\mathrm{a}}$ is the gross diffusion from air to soil and $Y_{\text {as }} f_{\mathrm{s}}$ is the gross diffusion from ground-surface soil to air. $Y_{\mathrm{as}}$ is the fugacity mass-transfer coefficient across the boundary between air and soil with units $\mathrm{mol} /\left(\mathrm{m}^{2}-\mathrm{Pa}-\mathrm{d}\right)$,

$$
Y_{\mathrm{as}}=\left[1 /\left(Z_{\mathrm{a}} U_{\mathrm{a})}+1 /\left(Z_{\mathrm{s}} U_{\mathrm{s}}\right)\right]^{-1} .\right.
$$

where, $U_{a}$ and $U_{s}$ are, respectively, the soil- and air-side mass transfer coefficients with units of velocity, $\mathrm{m} / \mathrm{d}$. Based on the work of Jury et. al. (1983), $U_{a}$ is estimated as $D_{\text {air }} /(0.005 \mathrm{~m})$, where $D_{\text {air }}$ is the diffusion coefficient of $H C B$ in air $\left(\mathrm{m}^{2} / \mathrm{d}\right)$, and $U_{s}$ is given by

$$
\mathrm{U}_{\mathrm{s}}=\frac{\left[\left(\alpha_{s}^{10 / 3} \mathrm{D}_{\mathrm{air}} \frac{\mathrm{H}}{\mathrm{RT}}+\phi_{s}^{10 / 3} \mathrm{D}_{\text {water }}\right) / \phi_{s}^{2}\right]}{(0.002 \mathrm{~m}) \times\left(\frac{\rho_{\mathrm{b}} \mathrm{K}_{\mathrm{Dsp}}}{1000}+\phi_{s}+\alpha_{s} \frac{\mathrm{H}}{\mathrm{RT}}\right)}
$$

where $\rho_{b}$ is the bulk density of the soil $\left(\mathrm{kg} / \mathrm{m}^{3}\right)$ and $D_{\text {water }}$ is the diffusion coefficient in pure water $\left(\mathrm{m}^{2} / \mathrm{d}\right)$, and other parameters are defined in Table 3 in the text.

The rate constant, $T_{\mathrm{aw}}$, accounts for gross diffusion, rain-water washout, and particle deposition losses from air to surface water and has the form

$$
T_{\mathrm{aw}}=\mathrm{f}_{\mathrm{arw}} \times \frac{\left(Y_{\mathrm{aw}}+\text { rain } \times Z_{\text {water }}+v_{\mathrm{d}} \times Z_{\mathrm{ap}} \times \frac{\rho \mathrm{b}_{\mathrm{a}}}{\rho \mathrm{s}_{\mathrm{s}}}\right)}{\left(Z_{\mathrm{a}} \times \mathrm{d}_{\mathrm{a}}\right)} .
$$


$Y_{\mathrm{aw}}$ is the fugacity mass-transfer coefficient across the boundary between air and water with units $\mathrm{mol} /\left(\mathrm{m}^{2}-\mathrm{Pa}-\mathrm{d}\right)$,

$$
Y_{\mathrm{aw}}=\left[1 /\left(Z_{\mathrm{a}} U_{\mathrm{a})}+1 /\left(Z_{\mathrm{w}} U_{\mathrm{w}}\right)\right]^{-1}\right.
$$

where, $U_{a}$ and $U_{w}$ are, respectively, the air- and water-side mass transfer coefficients with units of velocity, $\mathrm{m} / \mathrm{d}$. Based on the work of Southworth (1979), $U_{a}$ is estimated as $D_{\text {air }} /(0.014 \mathrm{~m})$ and $U_{w}$ is given by $D_{\text {water }} /(0.00024 \mathrm{~m})$.

\section{The Surface Soil (s) Compartment}

The surface-soil compartment represents the surface layer of soil in which losses include diffusion to air, diffusion to root-zone soil, infiltration to deeper soil layers, runoff to surface water, and transformation processes. The inventory, $N_{\mathrm{S}}$, in mol of contaminant in the ground-soil compartment is described by equation 5 in the text. $L_{\mathrm{S}}$ is the sum of all loss-rate constants from the ground-surface-soil compartment,

$$
L_{\mathrm{S}}=T_{\mathrm{sa}}+T_{\mathrm{so}}+T_{\mathrm{sw}}+R_{\mathrm{s}},
$$

where $L_{\mathrm{s}} N_{\mathrm{S}}$ is the sum of all losses from the soil compartment, mol/d; $T_{\mathrm{as}} N_{\mathrm{a}}$ is the gains from the air compartment, mol/d; $T_{\mathrm{sa}}$ and $T_{\mathrm{sw}}$ are the rate constants for resuspension losses to air, for gross diffusion losses to air and to deeper soil, for advection losses due to rain-water infiltration and for runoff losses to surface water, day $^{-1}$; and $R_{\mathrm{S}}$ is the rate constant for transformation losses, day ${ }^{-1}$. These loss-rate constants are given by

$$
\begin{aligned}
& T_{\mathrm{sa}}=\frac{Y_{\mathrm{as}}+\mathrm{v}_{\mathrm{d}} \times \mathrm{pb}_{\mathrm{a}} \times \frac{Z_{\mathrm{sp}}}{\rho \mathrm{s}_{\mathrm{s}}}}{Z_{\mathrm{s}} \times \mathrm{d}_{\mathrm{s}}}, \\
& T_{\mathrm{so}}=\frac{\text { recharge } \times Z_{\mathrm{water}}+Y_{\mathrm{ss}}}{Z_{\mathrm{s}} \times \mathrm{d}_{\mathrm{s}}}, \\
& T_{\mathrm{sw}}=\frac{\text { runoff } \times Z_{\mathrm{water}}+\text { erosion } \times \frac{Z_{\mathrm{sp}}}{\rho \mathrm{s}_{\mathrm{s}}}}{Z_{\mathrm{s}} \times \mathrm{d}_{\mathrm{s}}} \text {, and } \\
& \text { recharge }=\text { rain } \times\left(1-\mathrm{f}_{\text {arw }}\right)-\text { evapotrans }- \text { runoff. } .
\end{aligned}
$$


Equation $10 \mathrm{~A}$ reflects the assumption that resuspension of soil particles is, on average, equal to deposition.

\section{The Surface-Water (w) Compartment}

The surface-water compartment represents bodies of water in which losses include diffusion to air, diffusion to sediment, deposition to sediment, outflow to other surface-water bodies, and transformation processes. The inventory, $N_{\mathrm{W}}$, in mol of contaminant in the surface-water compartment is described by equation 6 in the text and $L_{\mathrm{w}}$ is the sum of all loss-rate constants from the ground-surface-soil compartment,

$$
L_{\mathrm{w}}=T_{\mathrm{wa}}+T_{\mathrm{wd}}+T_{\mathrm{wo}}+R_{\mathrm{w}}
$$

where $L_{\mathrm{w}} N_{\mathrm{w}}$ is the sum of all losses from the surface-water compartment, mol/d; $T_{\mathrm{aw}} N_{\mathrm{a}}$ is the gain by diffusion and deposition from the air compartment, mol/d; $T_{\mathrm{gw}} N_{\mathrm{g}}$ is the gain by runoff from the surface-soil compartment, mol/d; $T_{\mathrm{dw}} N_{\mathrm{d}}$ is the gain by diffusion and deposition from the sediment compartment, mol/d; $T_{\text {wa }}$ $T_{\mathrm{wd}}$, and $T_{\mathrm{wo}}$ are rate constants for gross diffusion loss to air, for deposition and gross diffusion losses to sediments, and for loss due to outflow, day ${ }^{-1}$; and $R_{\mathrm{w}}$ is the rate constant for transformation losses, day ${ }^{-1}$. The loss-rate constants are given by

$$
\begin{aligned}
& T_{\mathrm{wa}}=\frac{Y_{\mathrm{aw}}}{Z_{\mathrm{w}} \times \mathrm{d}_{\mathrm{w}}}, \\
& T_{\mathrm{wd}}=\frac{Y_{\mathrm{wd}}+\text { deposit } \times Z_{\mathrm{dp}} / \rho \mathrm{s}_{\mathrm{d}}}{Z_{\mathrm{w}} \times \mathrm{d}_{\mathrm{w}}}, \\
& T_{\mathrm{wo}}=\text { outflow } \times \frac{\left[Z_{\mathrm{water}}+\left(Z_{\mathrm{wp}} \times \rho \mathrm{b}_{\mathrm{w}} / \rho \mathrm{s}_{\mathrm{d}}\right)\right]}{Z_{\mathrm{w}} \times \mathrm{d}_{\mathrm{w}} \times \mathrm{f}_{\mathrm{arw}}} \text {, and } \\
& \text { outflow = inflow }+ \text { runoff }+ \text { rain } \times\left(\mathrm{f}_{\mathrm{arw}}\right)-\text { evaporate. }
\end{aligned}
$$




\section{Solutions for the Molar Inventories}

Equations 4 through 6 in the text and matrix inversion methods are used to solve for the steady-state inventories, $N_{\mathrm{i}}$, of contaminant in the three compartments included in the model. These solutions give the following relationships,

$$
\begin{aligned}
& N_{w}=\frac{\left[\frac{\mathrm{S}_{\mathrm{w}}}{\mathrm{L}_{\mathrm{w}}}+\frac{\mathrm{T}_{\mathrm{sw}} \times \mathrm{a}_{\mathscr{\sigma}}}{\mathrm{L}_{\mathrm{w}}}+\frac{\mathrm{T}_{\mathrm{aw}} \times \mathrm{S}_{\mathrm{a}}}{\mathrm{L}_{\mathrm{w}} \times \mathrm{L}_{\mathrm{a}}}+\frac{\mathrm{T}_{\mathrm{aw}} \times \mathrm{S}_{\mathrm{a}} \times \mathrm{a}_{\mathscr{Q}}}{\mathrm{L}_{\mathrm{w}} \times \mathrm{L}_{\mathrm{a}}}\right]}{\left[1-\frac{\mathrm{T}_{\mathrm{sw}} \times \mathrm{b}_{\mathscr{\sigma}}}{\mathrm{L}_{\mathrm{w}}}-\frac{\mathrm{T}_{\mathrm{aw}} \times \mathrm{T}_{\mathrm{sa}} \times \mathrm{b}_{\mathscr{Q}}}{\mathrm{L}_{\mathrm{w}} \times \mathrm{L}_{\mathrm{a}}}-\frac{\mathrm{T}_{\mathrm{aw}} \times \mathrm{T}_{\mathrm{wa}}}{\mathrm{L}_{\mathrm{w}} \times \mathrm{L}_{\mathrm{a}}}\right]} \\
& \mathrm{N}_{s}=\mathrm{a}_{\circledast}+\mathrm{b}_{\circledast} \times \mathrm{N}_{\mathrm{w}} \\
& N_{a}=\frac{S_{a}}{L_{a}}+\frac{T_{a s}}{L_{a}} \times N_{s}+\frac{T_{w a}}{L_{a}} \times N_{w}
\end{aligned}
$$

where,

$$
\begin{aligned}
& \mathrm{a}_{\varnothing}=\frac{\mathrm{T}_{\mathrm{as}} \times \mathrm{S}_{\mathrm{a}}}{\mathrm{L}_{\mathrm{s}} \times \mathrm{L}_{\mathrm{a}}} \times\left\{\left[1-\frac{\mathrm{T}_{\mathrm{as}} \times \mathrm{T}_{\mathrm{sa}}}{\mathrm{L}_{\mathrm{s}} \times \mathrm{L}_{\mathrm{a}}}\right]^{-1}\right\} \\
& \mathrm{b}_{\varnothing}=\frac{\mathrm{T}_{\mathrm{as}} \times \mathrm{T}_{\mathrm{wa}}}{\mathrm{L}_{\mathrm{s}} \times \mathrm{L}_{\mathrm{a}}} \times\left\{\left[1-\frac{\mathrm{T}_{\mathrm{as}} \times \mathrm{T}_{\mathrm{sa}}}{\mathrm{L}_{\mathrm{s}} \times \mathrm{L}_{\mathrm{a}}}\right]^{-1}\right\}
\end{aligned}
$$




\section{REFERENCES}

Benarie, M.M. (1980), Urban Air Pollution Modeling (MIT Press, Cambridge, MA).

Cess, R.D., M.-H. Zhang, G.L. Potter, H.W. Barker, R.A. Colman, D.A. Dazlich, A.D. Del Genio, M. Esch, J.R. Fraser, V. Galin. W.L. Gates, J.J. Hack. W.J. Ingram, J.T. Kiehl, A.A. Lacis, H. Le Treut, Z.-X. Li, X.-Z. Liang, J.-F. Mahfouf, B.J. McAvaney, V.P. Meleshko, J.-J. Morcrette, D.A. Randall, E. Roeckner, J.-F. Royer, A.P. Sokolov, P.V. Sporyshev, K.E. Taylor, W.-C. Wang, and R.T. Wetherald (1993), "Uncertainties in Carbon Dioxide Radiative Forcing in Atmospheric General Circulation Models," Science 262, 1252-1255.

Cohen, Y., W. Tsai, S.L. Chetty, and G.J. Mayer (1990), "Dynamic Partitioning of Organic Chemicals in Regional Environments: A Multimedia ScreeningLevel Approach," Environ. Sci. Technol. 24, 1549-1558.

Cohen, Y., and P.A. Ryan (1985), "Multimedia Modeling of Environmental Transport: Trichloroethylene Test Case," Environ. Sci. Technol. 9, 412-417.

Decisioneering, Inc. (1988-1993, 1994), Crystal Ball ${ }^{\circledR}$ Version 3.0-Forecasting and Risk Analysis for Spreadsheet Users, Decisioneering, Inc., Denver, CO (Software; User Manual; and Apple Macintosh Supplement to User Manual).

Gleick, P.L. (1987), "The Development and Testing of a Water Balance Model for Climate Impact Assessment," Water Resour. Res. 23, 1049-1061.

Hall, J.V., A.M. Winer, M.T. Kleinman, F.W. Lurmann, V. Brajer, and S.D. Colome (1992), "Valuing the Health Benefits of Clean Air," Science 255, 812-817.

Howard, P.H., Ed. (1989), Handbook of Environmental Fate and Exposure Data for Organic Chemicals. Volume I. Large Production and Priority Pollutants, (Lewis Publishers, Chelsea, MI), pp. 351-359.

Howard, P.H., R.S. Boethling, W.F. Jarvis, W.M. Meylan, and E.M. Michalenko, Eds. (1991), Handbook of Environmental Degradation Rates (Lewis Publishers, Inc., Chelsea, MI).

International Atomic Energy Agency (IAEA) (1989), Evaluating the Reliability of Predictions Made Using Environmental Transfer Models (International Atomic Energy Agency, Vienna, Austria), Safety Series No. 100.

Jury, W., W. Spencer, and W. Farmer (1983), "Behavior Assessment Model for Trace Organics in Soil: I. Model Description," J. Environ. Qual. 12, 558-564.

Karickhoff, S.W. (1981), "Semi-Empirical Estimation of Sorption of Hydrophobic Pollutants on Natural Sediments and Soils," Chemosphere 10, 833-846. 
Kempton, W., and P.P. Craig (1993), “European Perspectives on Global Climate Change," Environment 35(3), 16-20 and 41-45.

Lane, L.J., M.H. Nichols, and H.B. Osborn (1994), "Time Series Analyses of C' sbal Change Data," Environ. Pollut. 83, 63-68.

Lave, L.B., and H. Dowlatabadi (1993), "Climate Change: The Effects of Pe al Beliefs and Scientific Uncertainty," Environ. Sci. Technol. 27, 1962- 2.

Lindzen, R.S. (1994), "On the Scientific Basis for Global Warming Scena " ," Environ. Pollut. 83, 125-134.

MacCracken, M.C. (1988), Greenhouse Warming: What Do We Know? Presentation to the Conference on the Implications of Climatic Change for California, November 21, 1988, in San Francisco, CA, Lawrence Livermore National Laboratory, Livermore, CA, UCRL-99998.

MacCracken, M.C. (1991), The Challenge of Identifying Greenhouse-Gas-Induced Climatic Change, Lawrence Livermore National Laboratory, Livermore, CA, UCRL-JC-105967 Rev 1, prepared for submission to the Proceedings of the 1990 Global Change Institute on Earth System Modeling.

Mackay, D. (1979), “Finding Fugacity Feasible," Environ. Sci. Technol. 13, 1218-1223.

Mackay, D. (1991), Multimedia Environmental Models, the Fugacity Approach (Lewis Publishers, Chelsea, MI).

Mackay, D., and S. Paterson (1981), "Calculating Fugacity," Environ. Sci. Technol. 15, 1006-1014.

Mackay, D., and S. Paterson (1982), "Fugacity Revisited," Environ. Sci. Technol. 16, 654-660.

Mackay D., and S. Paterson (1991), "Evaluating the Multimedia Fate of Organic Chemicals: A Level-III Fugacity Model," Environ. Sci. Technol. 25, 427-436.

McKone, T.E. (1994), "Uncertainty and Variability in Human Exposures to Soil Contaminants Through Home-Grown Food: A Monte Carlo Assessment," Risk Analysis 14, 449-463.

McKone, T.E. (1993), CalTOX, A Multimedia Total-Exposure Model for I rardousWastes Sites Part I: Executive Summary, Lawrence Livermore $\mathrm{Na}$ ial Laboratory, Livermore, CA, UCRL-CR-111456PtI.

McKone, T.E., J.I. Daniels, F.F. Chiao, and D.P.H. Hsieh (1993), Intermedia i nsfer Factors for Fifteen Toxic Pollutants Released to Air Basins in Califor . $I$, Lawrence Livermore National Laboratory, Livermore, CA, UCRL-CF 115620, pp. 121-140. 
McKone, T.E., and D.W. Layton (1986), "Screening the Potential Risk of Toxic

Substances Using a Multimedia Compartment Model: Estimation of Human Exposure," Regul. Toxicol. Pharmacol. 6, 359-380.

McKone, T.E., L.B. Gratt, M.J. Lyon, and B.W. Perry (1987), GEOTOX Multimedia Compartment Model User's Guide, Lawrence Livermore National Laboratory, Livermore, CA UCRL-15913.

National Academy of Sciences (NAS), Policy Implications of Greenhouse Warming-Synthesis Panel, Committee on Science, Engineering, and Public Policy (1991), Policy Implications of Greenhouse Warming (National Academy Press, Washington, DC).

Soil Conservation Service (1975), Soil Taxonomy: A Basic System of Soil Classification for Making and Interpreting Soil Surveys (U.S. Government Printing Office, Washington, DC), U.S. Department of Agriculture, Handbook $\mathrm{N}^{\circ} .436$.

Southworth, G.R. (1979), "The Role of Volatilization in Removing Polycyclic Aromatics from Aquatic Environments," Bull. Environ. Contamin. Toxicol. 21, 507-514.

Thibodeaux, L.J. (1979), Chemodynamics: Environmental Movement of Chemicals in Air, Water, and Soil (John Wiley and Sons, New York, NY).

Turner, D.B. (1970), Workbook of Atmospheric Dispersion Estimates, U.S. Environmental Protection Agency, Research Triangle Park, NC, Office of Air Programs Publication No. AP-26, Rev. 1970 (Reprinted by Federal Emergency Management Agency, Washington, DC, January 1982; Publication $\mathrm{N}^{\circ}$. TD-18).

United States Department of Agriculture (USDA) (1978), Predicting Rainfall Erosion Losses, A Guide to Conservation Planning (U.S. Government Printing Office, Washington DC), U.S. Department of Agriculture, Handbook $N^{\circ} .537$.

United States Environmental Protection Agency (USEPA) (1993), Health Effects Assessment Summary Tables (HEAST), Annual Update for FY-1993, Office of Solid Waste and Emergency Response, United States Environmental Protection Agency, Washington, DC, 9200.6-303(93-1), EPA 540-R-93-058, PB93-921199 (March 1993), p. 3-19.

United States National Oceanic and Atmospheric Administration (USNOAA) (1974), Climates of the States, Volume II Western States (Water Information Center, Inc., Port Washington, NY).

van de Meent, D. (1990), "Modelling Intercompartment Transfer of Pollutants-The Case of Lead," Sci. Total Environ. 90, 41-54. 
van der Leeden, F., F.L. Troise, and D.K. Todd (1991), The Water Encyclopedia (Lewis Publishers, Chelsea, MI), second edition.

Whicker, F.W., and T.B. Kirchner (1987), "PATHWAY: A Dynamic Food-Chain Model to Predict Radionuclide Ingestion After Fallout Deposition," Health Phys. 52, 717-737.

World Health Organization (WHO) Task Group (1990), Potential Health Effects of Climatic Change, World Health Organization, Geneva, Switzerland, WHO/PEP/90/10, pp. 16-47. 